\title{
Thermodynamic structure of the convective boundary layer (CBL) over the Indian monsoon region during CAIPEEX campaigns
}

\author{
Sanjay Kumar Mehta ${ }^{1}$, Devendra Ojha ${ }^{2}$, Shyam Mehta ${ }^{3}$, Devarajan Anand ${ }^{2}$, Daggumati Narayana Rao ${ }^{1}$, \\ Vanmathi Annamalai ${ }^{1}$, Aravindhavel Ananthavel ${ }^{1}$, and Saleem $\mathrm{Ali}^{1}$ \\ ${ }^{1}$ SRM Research Institute, SRM University, Kattankulathur 603203, India \\ ${ }^{2}$ TIFR Balloon Facility, Hyderabad 500 062, India \\ ${ }^{3}$ Bose Institute, Kolkata 700091, India
}

Correspondence: Sanjay Kumar Mehta (sanjaykumar.r@res.srmuniv.ac.in, ksanjaym@gmail.com)

Received: 5 May 2017 - Revised: 13 November 2017 - Accepted: 13 November 2017 - Published: 22 December 2017

\begin{abstract}
Spatial and temporal variability in the convective boundary layer (CBL) height for the Cloud Aerosol Interaction and Precipitation Enhancement Experiment (CAIPEEX) study period are examined using the data collected from high-resolution radiosondes during May-September 2009 over the Indian monsoon region. In total, 57 radiosonde launchings were carried out at $\sim$ 11:00-17:00 IST over six different stations covering a large geographical region, ranging from latitude $\sim 13$ to $32^{\circ} \mathrm{N}$ and longitude 73 to $92^{\circ} \mathrm{E}$. Of the total 57 launchings, 17 were made during cloudy conditions during which relative humidity ( $\mathrm{RH}$ ) was found to be greater than $83 \%$ for an $\sim 1.0 \mathrm{~km}$ layer at various altitudes below $6 \mathrm{~km}$. Within the layer the difference between saturated equivalent potential temperature and equivalent potential temperature is small, and it satisfies the condition that $\mathrm{RH}>83 \%$ for about $1 \mathrm{~km}$ is considered as the cloudy layer. There are eight cases when the cloud-topped boundary layer (CTBL) and 19 cases when fair-weather boundary layer (FWBL) is observed. The CBL heights are obtained using thermodynamic profiles, which vary from $\sim 0.4$ to $2.5 \mathrm{~km}$ a.g.1. The formation of the cloud layers above the boundary layer generally lowers the CBL height and is responsible for its day-to-day variability. The development of the cloud beneath the boundary layer generally elevates the CBL, which is also responsible for the large day-to-day variability in the CBL. The FWBL identified using relative invariance of the thermodynamic profiles varies from $\sim 2.0$ to $5.5 \mathrm{~km}$, which is clearly marked by a local minimum in the refractivity gradient. During cloudy days, the CBL is found to be shallow and the surface temperature lower when compared to clear-sky days. The CBL and the lifting condensa-
\end{abstract}

tion level (LCL) heights are randomly related and are found to be at a lower height during cloudy days when compared to clear-sky days. Finally, the typical comparison between the CBL height obtained using thermodynamic profiles and backscattering profiles using Cloud-Aerosol Lidar and Infrared Pathfinder Satellite Observation (CALIPSO) is examined.

Keywords. Atmospheric composition and structure (biosphere-atmosphere interactions; cloud physics and chemistry; troposphere - composition and chemistry)

\section{Introduction}

The atmospheric boundary layer (ABL) plays an important role in the transportation of pollutants and anthropogenic emissions, moisture, heat, and momentum fluxes to the free atmosphere. The structure of the ABL is maintained by the strength of the turbulence-mixing (generated due to thermals during daytime and wind shear during night-time) processes. The ABL contains mainly four regimes: (i) the surface layer observed during both day and night, which forms adjacent to the ground where the temperature decreases super adiabatically; (ii) the convective boundary layer (CBL), which evolves during daytime; (iii) the stable (nocturnal) boundary layer (SBL/NBL) observed mainly at night-time, which, however, can also occur occasionally during daytime (Mehta et al., 2017); (iv) and the residual layer (RL), which is observed during night-time as a neutral layer. The evolution of the ABL is locally influenced by the surface characteristics and prevailing meteorological conditions (Stull, 1988; 
Garratt, 1992; Medeiros et al., 2005). The ABL has strong seasonal characteristics; however, it changes even within the season (Seidel et al., 2010; Bianco et al., 2011; Chan and Wood, 2013; Guo et al., 2016) and is mainly related to thermodynamic conditions of the atmosphere. Hence, understanding of the day-to-day weather conditions and their influence on the ABL variability is essential for air quality assessment and numerical weather simulations.

In clear-sky conditions, the growth of the CBL is mainly driven by the solar heating of the ground starting about half an hour after the sunrise. The thermals of the warm air (convective turbulence) rising from the ground create statistically unstable situations that cause intense mixing throughout the $\mathrm{CBL}$. With the increase in the surface temperature, the CBL grows and reaches its maximum height in the late afternoon ( 14:00 IST). The convective turbulence tends to mix, heat, moisture, and momentum uniformly in the vertical direction. The rising thermals cool while mixing and sink back down, forming a stable layer at the top of the CBL that is generally referred to as the entrainment zone (EZ). It is known that the presence of clouds has a large impact on the boundary layer structure as well as on the surface weather (Garratt, 1992; Medeiros et al., 2005; Miao et al., 2017). However, the growth of the CBL in cloudy conditions occurring at various levels (within, near, or above the CBL) is not well understood. The CBL evolution in the presence of clouds is relatively complex in nature due to the important role played by radiative fluxes and phase changes when compared to a clearsky (cloud free) CBL. Mainly three types of clouds, namely shallow cumulus, stratocumulus, and stratus, occur at the top boundary layer (Garratt, 1992; Medeiros et al., 2005). In the presence of CTBL, the CBL is nearly a mixed layer formed due to heat transfer from the warm ground surface and radiative cooling from the top of the cloud layer (Stull, 1988). Generally, the CTBL occurs beneath the CBL and is fully coupled to turbulent mixing. However, there are occasions when the cloud or sub-cloud layer may occur well below the inversion layer and the CBL is generally assigned as the top of the lowest cloud layer. Sometimes, the radiatively driven elevated mixed layer contains the cloud layer that is decoupled from the surface.

Generally, the boundary layer clouds tend to occur over the ocean where the low-level moisture sources from the sea surface evaporation are easily available (Stull, 1988). However, over the land the boundary layer clouds can occur due to cold air outbreaks over the sea, the development of anticyclonic regions over the ocean, onshore flow, and trade winds (Stull, 1988; Garratt, 1992; Bianco et al., 2011; Zhang et al., 2011; Zhou and Geerts, 2013). The Indian summer monsoon is dominated by synoptic-scale cloudiness and precipitations associated with a cycle of active and break spells (Webster et al., 1998; Goswami, 2005). There have been several studies on the ABL characteristics over the Indian region during summer monsoon season (Holt and Raman, 1987; Parasnis and Goyal, 1990; Raman et al., 1990; Kusuma et al., 1991;
Joseph and Sijikumar, 2004; Roja Raman et al., 2011; Satyanarayana Mohan and Narayana Rao, 2012; Sandeep et al., 2014, 2015; Mehta et al., 2017). In general, the CBL is shallower during the active monsoon conditions when compared to break monsoon conditions (Satyanarayana Mohan and Narayana Rao, 2012; Sandeep et al., 2014). In the active monsoon situations, the evolution of the CBL is delayed by $\sim 1-4 \mathrm{~h}$ when compared to weak episodes (Sandeep et al., 2014). The diurnal variation in the ABL is weak during the summer monsoon season when compared to the winter season (Mehta et al., 2017). There is a close association between the diurnal evolution of the low-level jet (LLJ) streams and the CBL (Sandeep et al., 2014). It was observed that both the LLJ and CBL were elevated during afternoon hours on the non-rainy (dry episode) days over Gadanki $\left(13.45^{\circ} \mathrm{N}\right.$, $\left.79.2^{\circ} \mathrm{E}\right)$. The lower tropospheric temperature inversions at about $2-3 \mathrm{~km}$ (generally representing the CBL) are observed to be weak during the break phase due to weakening of the LLJ (Muraleedharan et al., 2013). Raman et al. (1990) reported the distinct thermal structure of the ABL during premonsoon and monsoon months. Since the total net radiative input to the surface during the active monsoon is about 3 times less compared to the break monsoon phase, resulting in low-level air temperature differences in the boundary layer over the land surfaces (May et al., 2012), a shallower ABL is expected during the active monsoon. These studies indicate that the Indian summer monsoon plays a significant role in the evolution of the boundary layer within the season. However, the possible cause for such variations in the ABL characteristics and their thermodynamic structure in the presence of synoptic-scale weather systems prevailing during Indian summer monsoon season is not well understood (Holt and Raman, 1987).

During Indian summer monsoon season the intertropical convergence zone (ITCZ) shifts to $20-25^{\circ} \mathrm{N}$ latitude over the Indo-Gangetic plain, which is generally called a monsoon trough. The ITCZ is formed due to convergence of the northeasterly and southwesterly trade winds. The southeasterly trade wind from the southern Indian Ocean after crossing the Equator gets deflected by the Earth's rotation, which then becomes a southwesterly trade wind on the south side of the ITCZ over the Indian landmass. On the north side of the ITCZ, northeasterly trade winds prevail. Cloudiness and rainfall are generally associated with the monsoon trough. Over the ocean the trade wind inversions are a permanent feature and have been observed over the Atlantic (Augstein, 1978; Schubert et al., 1995), tropical eastern Pacific (Schubert et al., 1995; Johnson et al., 1996), and Indian oceans (Ramana et al., 2004), the Arabian Sea (Subrahamanyam and Ramachandran, 2003; Alappattu and Kunhikrishnan, 2010), and the Bay of Bengal (Alappattu and Kunhikrishnan, 2010), which is one of the characteristics of the marine boundary layer. In close analogy to the trade wind inversion layer over the ocean, the fair-weather boundary layer (FWBL) with a CBL below shallow cumulus is gen- 
erally observed over land (Medeiros et al., 2005). The formation mechanism of the FWBL is similar to that of the trade wind inversion layer (TWIL). The prevailing southwesterly trade winds bring moist air from the Arabian Sea and prevailing northeasterly trade winds bring dry warm air from the northern heated landmass. These trade wind regimes are capped from becoming deeper by the TWIL, which is caused by the descending limb of the Hadley cell circulation that brings cooler air aloft from the subtropical ridge. Shallow cumulus clouds are generally found within the trade wind regimes. These shallow cumulus clouds are frequently seen during the monsoon and pre-monsoon seasons over the Indian region above the CBL. In the CBL, the dry static energy and water vapour mixing ratio tend to remain constant with height, whereas the TWIL or FWBL is a stably stratified region that impedes vertical movement of air, where static energy increases sharply and mixing ratio decreases sharply with height. Thus, over the tropics, the layer between the TWIL and the surface is usually called the tropical boundary layer (Sengupta and Ramachandran, 1998).

High-resolution GPS radiosonde observations at about 11:00-16:00 IST for several days were made in campaign mode (for the Cloud Aerosol Interaction and Precipitation Enhancement Experiment (CAIPEEX) campaign) over the six stations in the Indian monsoon region during MaySeptember (southwest monsoon season) 2009. Making use of this dataset, the thermodynamic structure of the CBL and its day-to-day variations during the clear-sky and cloudy conditions are examined and the results are presented in this paper. The objectives of the present study are to (i) describe the nature of the CBL evolution in the presence of the clouds at different levels such as the cloud-top boundary layer and cloud with large vertical extent; (ii) examine the behaviour of the refractivity gradient with thermodynamic profiles, which will be useful in demarking the occurrence of the FWBL; and (iii) provide typical comparison of the CBL height detected using radiosonde and Cloud-Aerosol Lidar and Infrared Pathfinder Satellite Observation (CALIPSO).

\section{Data and methods}

\subsection{GPS radiosonde data}

As part of the CAIPEEX campaigns (Kulkarni et al., 2012), high-resolution GPS radiosonde (Vaisala RS-80) balloon launchings were conducted to obtain the thermodynamic structure of the CBL over six stations: Bangalore $\left(12.98^{\circ} \mathrm{N}\right.$, $\left.77.59^{\circ} \mathrm{E}, 922 \mathrm{~m}\right)$, Hyderabad $\left(17.48^{\circ} \mathrm{N}, 78.52^{\circ} \mathrm{E}, 552 \mathrm{~m}\right)$, Pune $\left(18.53^{\circ} \mathrm{N}, 73.80^{\circ} \mathrm{E}, 583 \mathrm{~m}\right)$, Guwahati $\left(26.10^{\circ} \mathrm{N}\right.$, $\left.91.59^{\circ} \mathrm{E}, 74 \mathrm{~m}\right)$, Bareilly $\left(28.42^{\circ} \mathrm{N}, 79.45^{\circ} \mathrm{E}, 153 \mathrm{~m}\right)$, and Pathankot $\left(32.26^{\circ} \mathrm{N}, 75.63^{\circ} \mathrm{E}, 299 \mathrm{~m}\right)$ in the Indian monsoon region. The radiosondes were launched mostly at midday (12:00-14:00 IST (GMT + 05:30)) and sometimes at $\sim$ 11:00 and $\sim$ 17:00 IST during each spell of the campaign, which lasted between 3 to 12 days continuously during MaySeptember 2009, covering the pre-onset to withdrawal of the Indian summer monsoon (May-September). Figure 1 shows the Indian map indicating the launching periods over different stations. The experiment above was conducted by the team members located at the base station Hyderabad. The experiment was conducted in three rounds as indicated in Fig. 1. In the first round, launchings were carried out at Pune, Pathankot, Bangalore, and Hyderabad during 1319 May, 23-28 May, 2-4 June, and 11-22 June, respectively. In the second round, launchings were carried out at Bangalore, Bareilly, and Hyderabad during 27 June-7 July, 1722 July, and 12-16 August, respectively. In the third and last round, launchings were performed at Guwahati, Pune, and Hyderabad during 2-9 September, 19-23 September, and 27-30 September, respectively. In total 57 launchings were carried out as listed in Table 1. Vertical profiles of temperature $(T)$, pressure $(P)$, relative humidity $(\mathrm{RH})$, zonal $(U)$ and meridional $(V)$ winds, latitude, longitude, and altitude were collected with a height resolution of 25-30 m (sampled at $5 \mathrm{~s}$ intervals). The ascent rate of the balloon is about 4 $5 \mathrm{~m} \mathrm{~s}^{-1}$. In this study, we have used ascending profiles of the atmospheric parameters. All the atmospheric parameters collected are uniformly gridded to $30 \mathrm{~m}$ height resolution. Quality checks are then applied to remove any further outliers arising due to various reasons to ensure high-quality data (Mehta et al., 2011). The uncertainties in the pressure, temperature, $\mathrm{RH}$, wind speed, and wind direction measurements are $1.0 \mathrm{hPa}, 0.5 \mathrm{~K}, 5 \%, 1 \mathrm{~m} \mathrm{~s}^{-1}$, and $5^{\circ}$, respectively, in the troposphere. The averaged vertical profiles of the temperature, $\mathrm{RH}$, zonal wind, and meridional wind from the surface up to $25 \mathrm{~km}$ for three different rounds are shown in Fig. S1.

\subsection{CAIPEEX aircraft experiment}

CAIPEEX aircraft experiments are conducted to understand aerosol-cloud interaction and precipitation enhancement potential during May-September 2009. The measurements of the vertical profiles of the clouds and aerosol up to about 6$7 \mathrm{~km}$ from the surface were carried out using airborne instruments during CAIPEEX. The data can be obtained upon request from the website http://www.tropmet.res.in/ caipeex/. Out of more than 30 aircraft observations $(\sim 120 \mathrm{~h}$ of flying was performed during the period) (Kulkarni et al., 2012), 16 observations over Hyderabad (16-22 June and 15-16 August 2009), Pune (19-20 May 2009), and Pathankot (2324 May 2009) used in this study are available online. The measurements of the aerosol and clouds were carried out using instrumented Piper Cheyenne aircraft whose descriptions are detailed in Kulkarni et al. (2012). The observations were collected during the isolated growing cumulus clouds. These data are obtained at intervals of $1 \mathrm{~s}$. In this study, we have used liquid water content (LWC) to verify the cloud layer identification using RH profiles. Whenever LWC is found to be greater than zero and the total of cloud droplets is greater 
Table 1. List of sites where radiosonde launchings were conducted under the CAIPEEX campaign during May-September 2009 with the latitude, longitude, and altitude of the launching sites above mean sea level; periods of observation; and numbers of launchings. The dates of monsoon onset and withdrawal and of the simultaneous CALIPSO and radiosonde observations are also listed.

\begin{tabular}{|c|c|c|c|c|c|c|c|}
\hline Sites & $\begin{array}{r}\text { Latitude } \\
\qquad\left({ }^{\circ} \mathrm{N}\right)\end{array}$ & $\begin{array}{r}\text { Longitude } \\
\left({ }^{\circ} \mathrm{E}\right)\end{array}$ & $\begin{array}{r}\text { Altitude } \\
(\mathrm{m})\end{array}$ & Periods & $\begin{array}{l}\text { Onset/ } \\
\text { withdrawal }\end{array}$ & $\begin{array}{r}\text { No. of } \\
\text { launchings }\end{array}$ & $\begin{array}{l}\text { CALIPSO } \\
\text { passes }\end{array}$ \\
\hline Bangalore & 12.98 & 77.59 & 922 & $\begin{array}{l}\text { 2-4 Jun } \\
27 \text { Jun-5 Jul }\end{array}$ & 25-31May/24 Oct & 12 & 29 Jun \\
\hline Hyderabad & 17.48 & 78.52 & 552 & $\begin{array}{l}\text { 11-22 Jun } \\
\text { 12-16 Aug } \\
27-30 \mathrm{Sep}\end{array}$ & 21-23 Jun/24 Oct & 21 & 15 Jun, 28 Sep \\
\hline Pune & 18.53 & 73.80 & 583 & $\begin{array}{l}\text { 13-16 May } \\
19-23 \text { Sep }\end{array}$ & 21-23 Jun/11-23 Oct & 9 & None \\
\hline Guwahati & 26.10 & 91.59 & 74 & $2-7 \mathrm{Sep}$ & 8-10 Jun/11-12 Oct & 5 & $4 \mathrm{Sep}, 6 \mathrm{Sep}$ \\
\hline Bareilly & 28.42 & 79.45 & 153 & 17-22 Jul & 29 Jun/26-27 Sep & 5 & None \\
\hline Pathankot & 32.26 & 75.63 & 299 & 23-28 May & 30 Jun/23-25 Sep & 5 & 23 May \\
\hline
\end{tabular}

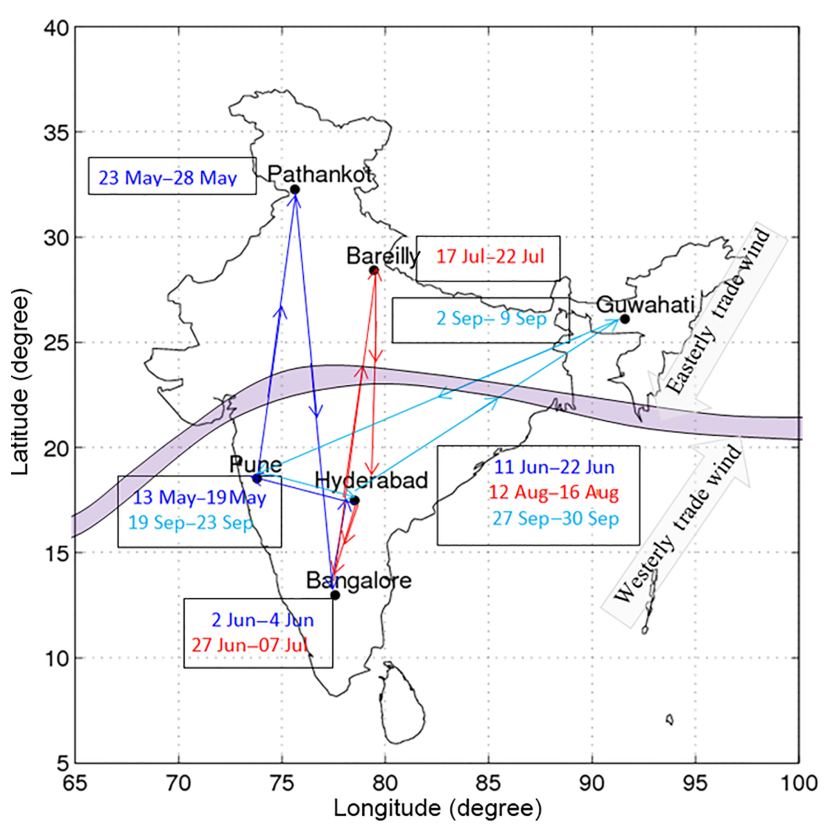

Figure 1. Map showing high-resolution GPS radiosonde launchings in three rounds during May-September 2009 over the Indian monsoon region. The first round (blue), second round (red), and third round (cyan) were conducted during May-June, July-August, and September, respectively.

than $20 \mathrm{~cm}^{-3}$ for a duration of at least $3 \mathrm{~s}$, the presence of clouds is indicated (Morwal et al., 2012).

\subsection{Infrared brightness temperature (TBB) data}

During the Indian summer season, clouds and rain often prevail over the Indian region. In order to understand the role of clouds in the formation and maintenance of the CBL, we have used infrared (IR) brightness temperature (TBB) values obtained from the Climate Prediction Center, NOAA, available at a time resolution of $1 \mathrm{~h}$ and spatial resolution of $0.03^{\circ} \times 0.03^{\circ}$. This is globally merged, fullresolution $(\sim 4 \mathrm{~km})$ IR data formed from the $\sim 11 \mu \mathrm{m} \mathrm{IR}$ channels aboard the GMS-5, GOES-8, Goes-10, Meteosat-7, and Meteosat- 5 geostationary satellites. The data have been corrected for zenith angle dependence to reduce discontinuities between adjacent geostationary satellites. For this study, we averaged the TBB data into a $0.1^{\circ}$ latitude $\times 0.1^{\circ}$ longitude grid around each of the stations listed in Table 1 and collected for each launching. The brightness temperature height (BTH) is obtained from the radiosonde temperature profiles as the altitude corresponding to the averaged TBB.

\subsection{CALIPSO total attenuated backscatter data}

As mentioned earlier, the radiosonde launchings were mostly carried out during midday, which provides an opportunity to compare and validate the CBL evolution using CALIPSO measurements over wide spatial and temporal scales in the Indian monsoon region. CALIPSO is the part of the Afternoon (A-Train) Constellation of satellites, which has an Equator crossing time of about 13:30 local solar time and a 16-day repeat cycle (Winker et al., 2007, 2009). For the present study, we have used version 2 Level 1B (CAL_LID_L1) data. CALIPSO provides data at a horizontal resolution of $333 \mathrm{~m}$, vertical resolution of $30 \mathrm{~m}$, and time resolution of $0.05 \mathrm{~s}$ below $8 \mathrm{~km}$. We have searched CALIPSO passes within $\pm 0.5^{\circ}$ latitude and $\pm 1^{\circ}$ longitude of each station and collected the data for the nearest proximity. Out of 57 profiles, we have observed only six simultaneous radiosonde and CALIPSO observations as listed in the Table 1.

\subsection{Method of analysis}

We have calculated the vertical profiles of the potential temperature $(\theta)$, virtual potential temperature $\left(\theta_{\mathrm{v}}\right)$, equivalent potential temperature $\left(\theta_{\mathrm{e}}\right)$, saturated equivalent potential temperature $\left(\theta_{\mathrm{es}}\right)$, specific humidity $(q)$, and radio refractivity (N) using the observed $T, P$, and RH data over the six 
(a) Bangalore, $13.04^{\circ} \mathrm{N}, 75.59^{\circ} \mathrm{E}, 952 \mathrm{~m}$

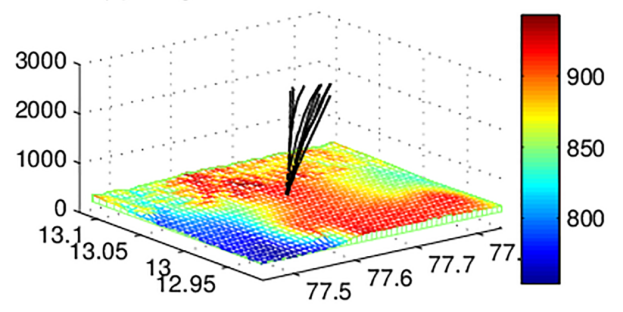

(c) Pune, $18.53^{\circ} \mathrm{N}, 73.80^{\circ} \mathrm{E}, 583 \mathrm{~m}$

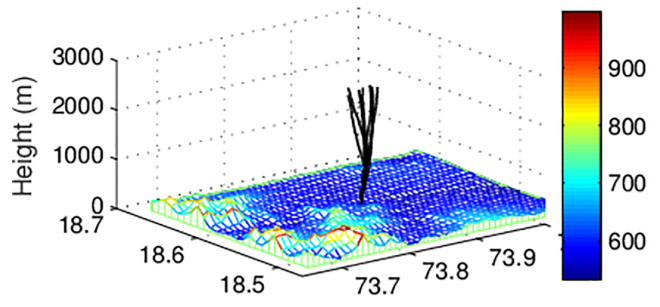

(e) Bareilly, $28.42^{\circ} \mathrm{N}, 79.45^{\circ} \mathrm{E}, 153 \mathrm{~m}$

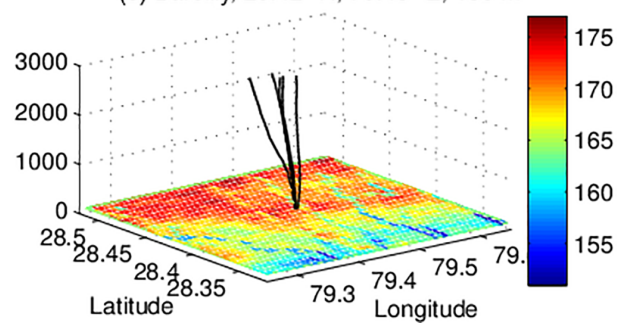

(b) Hyderabad, $17.48^{\circ} \mathrm{N}, 78.52^{\circ} \mathrm{E}, 552 \mathrm{~m}$

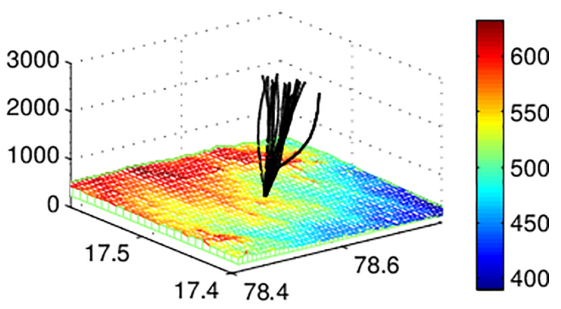

(d) Guwahati, $26.10^{\circ} \mathrm{N}, 91.59^{\circ} \mathrm{E}, 74 \mathrm{~m}$

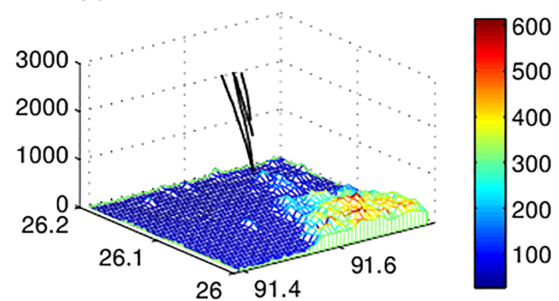

(f) Pathankot, $32.26^{\circ} \mathrm{N}, 75.63^{\circ} \mathrm{E}, 299 \mathrm{~m}$

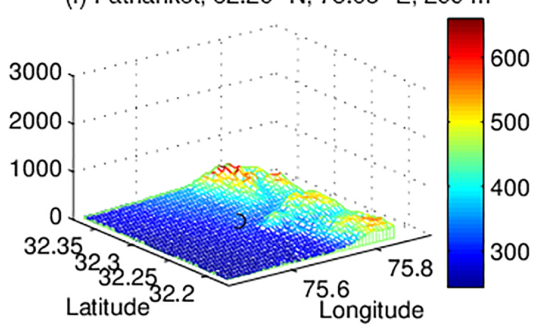

Figure 2. Topographical features surrounding the locations of radiosonde launch over the six sites: (a) Bangalore, (b) Hyderabad, (c) Pune, (d) Guwahati, (d) Bareilly, and (e) Pathankot in the Indian monsoon region, along with profiles of balloon trajectories from the surface up to $3 \mathrm{~km}$.

stations. The radio refractivity or simply refractivity in the neutral atmosphere is given by $N=77.6 \frac{P}{T}+3.73 \times 10^{-5} \frac{P_{\mathrm{w}}}{T^{2}}$, where $P_{\mathrm{w}}$ is water vapour pressure. These thermodynamic profiles are obtained in order to understand the behaviour of the CBL in the clear-sky and cloudy atmospheres. The knowledge of the boundary layer in the presence of cloud is limited when compared to a cloud-free CBL, which is mainly driven by surface heating (Garratt, 1992). In the clearsky conditions or dry atmosphere the estimation of the CBL height is relatively easy and can be identified using either the altitude of maximum in the temperature gradients or minimum in the moisture gradients (Mehta et al., 2017). In the cloudy atmosphere, the boundary layers are identified using the relative invariance of $\theta, \theta_{\mathrm{v}}, \theta_{\mathrm{e}}, \theta_{\mathrm{es}}$, and $q$ (Betts and Albrecht,1987). The presence of the moist air and the phase changes are generally studied by use of the $\theta_{\mathrm{v}}$ and $\theta_{\mathrm{e}}$ profiles. The CTBL often corresponds to a layer well mixed with regards to $\theta_{\mathrm{e}}$ and $q$ (Deardorff, 1981). Below the cloud base, a well-mixed layer may exist with constant $\theta$ and $\theta_{\mathrm{V}}$ but not in the cloud layer where they are not conserved. Within the cloud layer, $\theta_{\mathrm{v}}$ varies moist adiabatically. The altitude of maximum backscatter coefficient in the mean signal repre- sents the sharp decrease in the aerosol content above and is generally taken as the CBL top (Melfi et al., 1985; Jordan et al., 2010; McGrath-Spangler and Denning, 2012, 2013). In this study, the CBL height from CALIPSO data is identified as the local maxima in the logarithm of the total attenuated backscatter ratio (Zhang et al., 2016).

The lifting condensation level (LCL) is defined as the height at which an unsaturated air parcel becomes saturated $(\mathrm{RH} \geq 100 \%)$ when it is cooled by dry adiabatic lifting (Wallace and Hobbs, 2006). It provides an empirical estimate of the cloud base height. If the LCL lies beneath the capping inversion, then the CTBL is assumed to exist, with cloud usually coinciding with the inversion base. The temperature $\left(T_{\mathrm{LCL}}\right)$ and height $\left(Z_{\mathrm{LCL}}\right)$ of the LCL is obtained using the following equations (Bolton, 1980; Mehta et al., 2017):

$$
\begin{aligned}
T_{\mathrm{LCL}} & =\frac{2840}{3.5 \ln \left(T_{30 \mathrm{~m}}\right)-\ln \left(P_{\mathrm{w} 30 \mathrm{~m}}\right)-4.805}+55 \\
Z_{\mathrm{LCL}} & =Z_{30 \mathrm{~m}}-\left(T_{\mathrm{LCL}}-T_{30 \mathrm{~m}}\right) / \tau_{\mathrm{d}},
\end{aligned}
$$



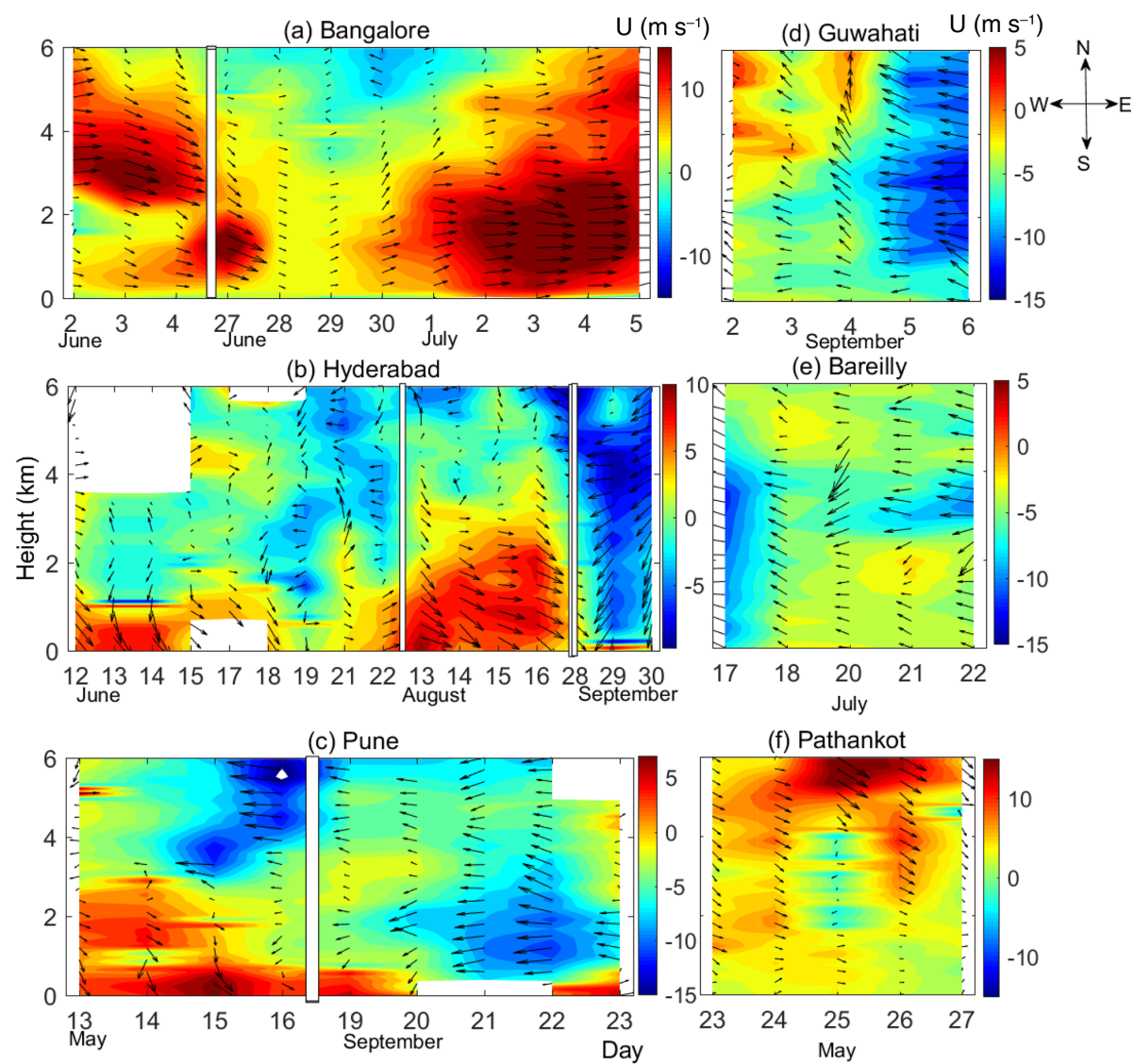

Figure 3. Contour plots of the zonal wind $(U)$ along with wind directions over (a) Bangalore, (b) Hyderabad, (c) Pune, (d) Guwahati, (e) Bareilly, and (f) Pathankot as listed in Table 1 in the increasing order of latitude over the Indian monsoon region during May to September 2009.

where $T_{30 \mathrm{~m}}$ and $P_{\mathrm{w} 30 \mathrm{~m}}$ are temperature and water vapour pressure at $30 \mathrm{~m}$ height, respectively, and $\tau_{\mathrm{d}}$ is dry adiabatic lapse rate.

\section{Results}

\subsection{Topography, balloon trajectory, and background meteorological conditions over six sites}

Figure 2 shows the topography and vertical profiles of the balloon's trajectory from the surface up to $3 \mathrm{~km}$ observed over the six sites in the Indian monsoon region as listed in Table 1 for the period during May-September 2009. The vertical profiles of the latitude and longitude were not recorded over Pathankot (Fig. 2f) and hence the balloon's trajectories are not shown. These trajectories show that the balloon over these sites flew almost vertically and drifted only about $0.1^{\circ}$ and $0.1^{\circ}$ latitude and longitude, respectively, below $3 \mathrm{~km}$. Bangalore, Hyderabad, and Bareilly are located at 922, 552, and $153 \mathrm{~m}$ above the mean sea level (a.m.s.l.), respectively, and the landscape is nearly uniform surrounding the launching site (Fig. 2a, b, and e). Whereas Pune, Guwa- hati, and Pathankot are located at 583, 74, and 299 m a.m.s.1., respectively, they are surrounded by complex hills (Fig. 2c, $\mathrm{d}$, and $\mathrm{f}$ ). Pune is located on the lee side of the Western Ghats, which have complex hills (e.g. Vetal Hill) with an altitude of about $700-900 \mathrm{~m}$ in the southeastern part of the launching site (Fig. 2b). Guwahati is surrounded by Bharalu tributaries of the Brahmaputra River and hills (e.g. Nilanchal hill) with a height of about $300-600 \mathrm{~m}$ to the west of the launching site (Fig. 2d). Pathankot is surrounded by the Ravi and Chakki rivers and Siwalik foothills with a height of about 400-600 m in the east (Fig. 2f).

During the Indian summer monsoon season the LLJ prevails over the Indian subcontinent with a jet core at $\sim 1.5 \mathrm{~km}$. However, the LLJ core speed and its vertical extent vary with the active and break episodes of the monsoon. The zonal wind speed $(U)$ and wind direction from the surface up to $6 \mathrm{~km}$ over the six different stations are shown in Fig. 3. Over Bangalore (Fig. 3a), the wind is westerly to northwesterly with a maximum zonal wind of $\sim 10-15 \mathrm{~m} \mathrm{~s}^{-1}$ at $\sim 3 \mathrm{~km}$ during 2-4 June 2009. The LLJ core is observed to be at $\sim 1.0 \mathrm{~km}$ on 27 June 2009 , which becomes weaker during 28-29 June 2009 and gradually intensified to $\sim 15 \mathrm{~m} \mathrm{~s}^{-1}$ 
at $1.5 \mathrm{~km}$ during 30 June-5 July 2009 . Over Hyderabad (Fig. 3b), zonal winds were northwesterly to northerly below $1.0 \mathrm{~km}$, with a LLJ core speed of about $5-10 \mathrm{~m} \mathrm{~s}^{-1}$ during 12-14 June 2009, which became weaker during 1521 June 2009. During 13-16 August 2009, westerly and northwesterly winds prevailed up to an altitude of $\sim 3.0 \mathrm{~km}$ with a wind core at $\sim 1.5 \mathrm{~km}$. Northeasterly and easterly winds prevailed above the westerly wind. During September as the southwest monsoon withdrew, northeasterly trade winds prevailed during 28-30 September 2009. Similarly, over Pune (Fig. 3c), weak westerly wind up to $\sim 3.0 \mathrm{~km}$ is observed during 13-16 May 2009 prior to the onset of the summer monsoon. During 16-19 September 2009 (as the summer monsoon withdrew), easterly winds prevailed as expected. As Guwahati, Bareilly and Pathankot (Fig. 3d-e) lie in the northern part of the ITCZ, northeasterly or easterly wind is expected to dominate. Over Guwahati, easterlies prevailed during 2-6 September 2009. Similarly, over Bareilly, weak easterlies prevailed. However, over Pathankot, the westerlies dominated during 23-27 May 2009 before the onset of the summer monsoon, which is a well-known wind pattern in the northern part of India during the pre-monsoon season.

\subsection{Evolution of the CBL in clear-sky conditions}

The typical vertical profiles of $\theta, \theta_{\mathrm{v}}, \theta_{\mathrm{e}}, \theta_{\mathrm{es}}, q, N$, and $N^{\prime}$ (gradient of $N$ ) over Bangalore, Hyderabad, Pune, Guwahati, Bareilly, and Pathankot for the case of the dry ABL during 11:00-15:00 IST up to $6 \mathrm{~km}$ altitude are shown in Fig. 4a-f, respectively. Over Bangalore, the convectively mixed layer through which vertical gradients of $\theta, \theta_{\mathrm{v}}, \theta_{\mathrm{e}}$, and $q$ are nearly zero (adiabatically stratified) up to $\sim 1.0 \mathrm{~km}$ is observed at 11:12 IST during 4 June 2009 (Fig. 4a). At the top of the $\mathrm{CBL}$, the refractivity sharply decreases forming minima in $N^{\prime}$, which is generally used to identify the CBL height especially using GPS radio occultation data, and it is preferred over the use of $\theta$ and $q$ (Basha and Ratnam, 2009). However, it should be noted that the multiple local minima can be seen in $N^{\prime}$ and the one that is at a minimum most below $3.5 \mathrm{~km}$ is identified as the CBL (Chan and Wood, 2013). Fixing the height criterion of $3.5 \mathrm{~km}$ as the upper limit is generally done to avoid mid-level inversions, if any. In cases in which more than one minimum is found below $3.5 \mathrm{~km}$, the lowest minimum with a value greater than $80 \%$ of the main minimum is considered as the CBL top (Mehta et al., 2017). Here, we have also avoided the minimum forming very near to the surface, which does not characterize the CBL. Within the CBL, the $\mathrm{RH}$ at the surface is about $50 \%$, which characterizes a dry boundary layer in which the temperature decreases nearly as much as the dry adiabatic lapse rate. The top of the CBL is capped by an inversion layer or EZ with a thickness of about $0.17 \mathrm{~km}$, which is evident in all the thermodynamic parameters. Above the CBL, both $\theta$ and $\theta_{\mathrm{v}}$ increase (stably stratified) with environmental lapse rate, whereas both $\theta_{\mathrm{e}}$ and $\theta_{\mathrm{es}}$ decrease with height up to $\sim 3.15 \mathrm{~km}$, indicating a conditionally unstable atmosphere (Ramana et al., 2004). The top of the conditionally unstable layer is capped by an another inversion layer in which $\theta, \theta_{\mathrm{v}}$, and $\theta_{\mathrm{es}}$ increase but $\theta_{\mathrm{e}}$ and $q$ decrease more (Betts and Albrecht, 1987). This inversion layer is generally characterized as the TWIL over the ocean and is marked by a maximum in $\theta_{\mathrm{es}}$ with a corresponding minimum in $\theta_{\mathrm{e}}$ (Betts and Albrecht, 1987). As mentioned earlier, over land the TWIL is referred to as the FWBL, which is observed at $\sim 3.15 \mathrm{~km}$ and is also identified using local minima in $N^{\prime}$. Note that there is no temperature inversion $(\Delta T>0)$ observed at the FWBL (See Fig. S2a).

Figure $4 \mathrm{~b}$ shows the typical evolution of the CBL through which vertical gradients of $\theta, \theta_{\mathrm{v}}, \theta_{\mathrm{e}}, \theta_{\mathrm{es}}, q$, and $N$ are zero (adiabatically stratified) up to $\sim 0.96 \mathrm{~km}$ over Hyderabad at 14:20 IST during 16 August 2009. Within the CBL, although the RH from the surface to the CBL is about $60 \%$, the temperature decreases dry adiabatically indicating a dry ABL. Above the CBL, both $\theta_{\mathrm{e}}$ and $\theta_{\mathrm{es}}$ decrease slowly with height and the difference between them also decreases with height. The $\mathrm{RH}$ is about $75 \%$, indicating a moist adiabatic layer up to $\sim 4.50 \mathrm{~km}$. It can be seen that the $\theta_{\mathrm{e}}$ is $\sim 349 \mathrm{~K}$ at the surface and $\approx 340 \mathrm{~K}$ above the $\mathrm{CBL}$, and there is a very weak transition layer from the CBL to above indicating the presence of the moist layer. The top of the moist layer is capped by the FWBL in which $\theta, \theta_{\mathrm{v}}$, and $\theta_{\mathrm{es}}$ increase but $\theta_{\mathrm{e}}, \mathrm{RH}$, $q$, and $N$ decrease more with a local minimum in $N^{\prime}$. In this case we observed the temperature inversion at about the freezing height (Johnson et al., 1996) (see Fig. S2b).

Figure $4 \mathrm{c}$ shows the typical evolution of the CBL through which vertical gradients of $\theta, \theta_{\mathrm{v}}$, and $\theta_{\mathrm{e}}$ are nearly zero (adiabatically stratified) in the shallow layer up to $\sim 0.45 \mathrm{~km}$ over Pune at 11:00 IST during 15 May 2009. The CBL is capped by a strong EZ with a thickness of $0.40 \mathrm{~km}$. Above the CBL, both $\theta$ and $\theta_{\mathrm{v}}$ are again nearly constant (adiabatically stratified) with a height up to $\sim 3.50 \mathrm{~km}$, indicating a dry adiabatic layer. Though $\theta_{\mathrm{e}}$ is also nearly constant in this layer, it does not represent the moist layer as RH is extremely low $\sim 30 \%$. $\theta_{\text {es }}$ strongly decreases with height above the CBL up to $\sim 3.50 \mathrm{~km}$, indicating that this layer is a convectively unstable layer. The top of this layer is capped by the FWBL in which $\theta, \theta_{\mathrm{v}}$, and $\theta_{\mathrm{es}}$ increase but $\theta_{\mathrm{e}}, \mathrm{RH}, q$, and $N$ decrease more with a local minimum in $N^{\prime}$. Similar to Fig. S4a, there is no temperature inversion observed at the FWBL (See Fig. S2c).

Unlike previous cases, Fig. $4 \mathrm{~d}$ shows the typical evolution of the CBL in which $\theta$ and $\theta_{\mathrm{v}}$ increase (stably stratified), whereas $\theta_{\mathrm{e}}, \theta_{\mathrm{es}}, q$, and $N$ decrease with height up to $\sim 1.45 \mathrm{~km}$, which is defined based on the minimum gradient in $N^{\prime}$ over Guwahati at 14:58 IST during 2 September 2009. CBL height is also identified as the altitude of the maximum gradients in $\theta$ and $\theta_{\mathrm{v}}$ and minimum gradients in $\mathrm{RH}$ and $q$ (figure not shown) (Mehta et al., 2017). Within the CBL, the air is not completely mixed and is conditionally unstable. Above the CBL, $\theta$ and $\theta_{\mathrm{v}}$ continue to increase while $q$ and $N$ 


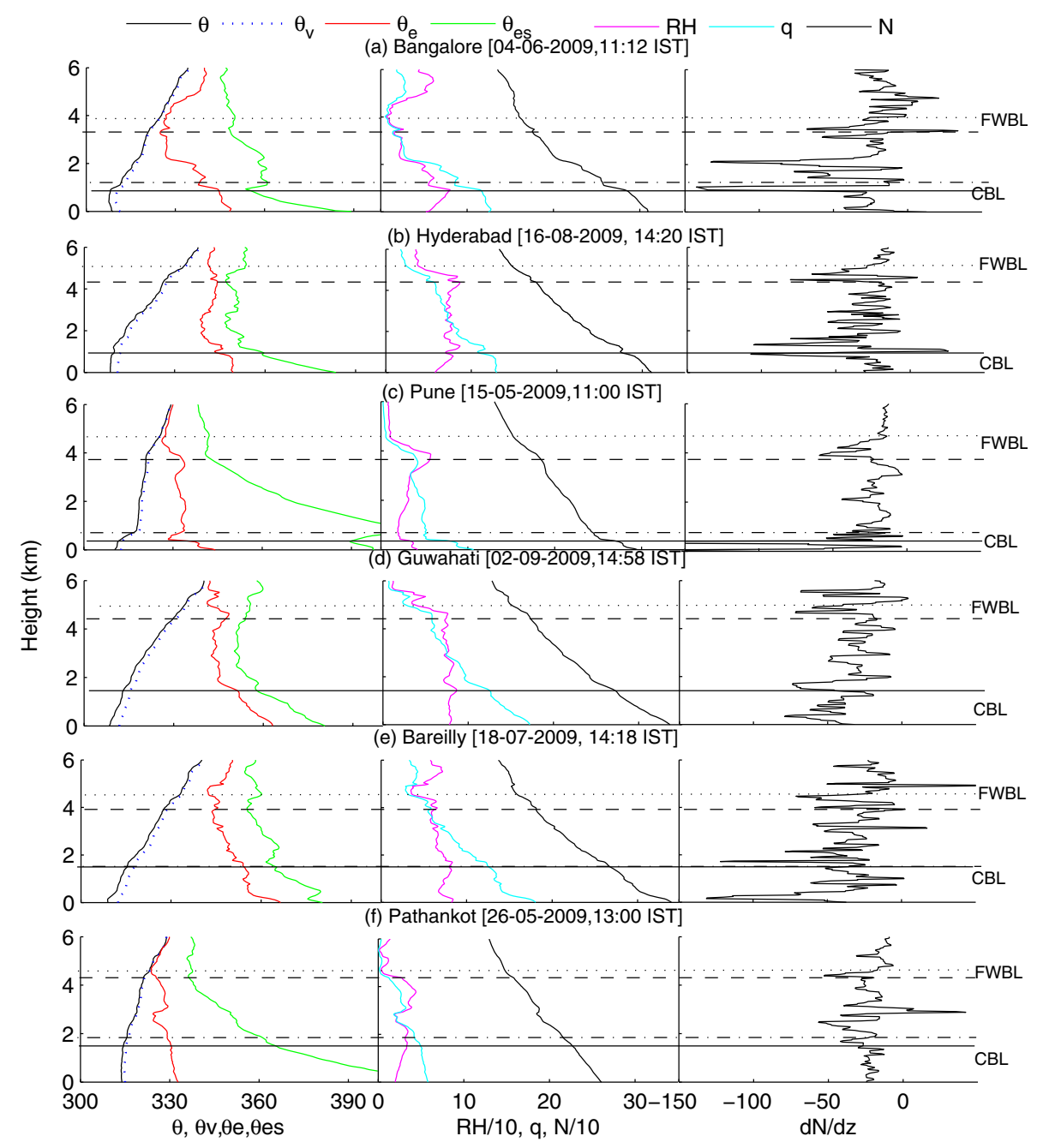

Figure 4. The vertical profiles of potential temperature $(\theta)$, virtual potential temperature $\left(\theta_{\mathrm{V}}\right)$, equivalent potential temperature $\left(\theta_{\mathrm{e}}\right)$, saturated equivalent potential temperature $\left(\theta_{\mathrm{es}}\right)$, relative humidity $(\mathrm{RH})$, specific humidity $(q)$, refractivity $(N)$, and refractivity gradient observed over (a) Bangalore, (b) Hyderabad, (c) Pune, (d) Guwahati, (e) Bareilly, and (f) Pathankot indicating the convective boundary layer (CBL) and the fair-weather boundary layer (FWBL) during the Indian summer monsoon season (JJAS) in 2009. Solid and dashed-dotted lines represent the bottom and top of the CBL, respectively, and dashed and dotted lines represent the bottom and top of the FWBL, respectively.

continue to decrease and $\theta_{\mathrm{e}}$ and $\theta_{\mathrm{es}}$ are almost constant with a height up to $4.50 \mathrm{~km}$. As the difference between $\theta_{\mathrm{e}}$ and $\theta_{\mathrm{es}}$ decreases with height and $\mathrm{RH}$ is $\sim 75 \%$ throughout the layer, a moist layer (temperature lapse rate about $4-6 \mathrm{~K} \mathrm{~km}^{-1}$; see Supplement Fig. S1d) above the CBL is indicated, as shown in Fig. 4b. The top of this layer is capped by the FWBL in which $\theta, \theta_{\mathrm{v}}$, and $\theta_{\mathrm{es}}$ increase but $\theta_{\mathrm{e}}, \mathrm{RH}, q$, and $N$ decrease more and have a local minimum in $N^{\prime}$. In this case we observed the temperature inversion at the FWBL, which corresponds to the altitude of the freezing height similar to Fig. $4 \mathrm{~b}$ (see Supplement Fig. S2d).

Similar to Fig. 4d, Fig. 4e shows the typical evolution of the CBL in which $\theta$ and $\theta_{\mathrm{v}}$ increase, whereas $\theta_{\mathrm{e}}, \theta_{\mathrm{es}}, q$, and $N$ decrease with height up to $\sim 1.50 \mathrm{~km}$ over Bareilly at 14:18 IST during 18 July 2009. Above the CBL, the difference between $\theta_{\mathrm{e}}$ and $\theta_{\mathrm{es}}$ decrease with height up to $4.0 \mathrm{~km}$ and $\mathrm{RH}$ is $\sim 66 \%$ throughout the layer, indicating the moist layer (temperature lapse rate about $4-6 \mathrm{~K} \mathrm{~km}^{-1}$; see Fig. S1e) above the CBL. Similarly, the top of this layer is capped by the FWBL and has a local minimum in $N^{\prime}$. Similar to Fig. $4 \mathrm{~b}$ and d, the top of the FWBL is also marked by the temperature inversion at freezing height (See Supplement Fig. S2e).

Figure $4 \mathrm{f}$ shows the typical evolution of the CBL through which vertical gradients of $\theta$ and $\theta_{\mathrm{v}}$ are nearly zero (adiabatically stratified) up to $\sim 1.50 \mathrm{~km}$ over Pathankot at 13:00 IST during 26 May 2009. Within the CBL the temperature decreases dry adiabatically, indicating a dry CBL. Above the CBL, $\theta_{\mathrm{e}}$ is nearly constant and $\theta_{\mathrm{es}}$ strongly decreases with height up to $4.50 \mathrm{~km}$. Though $\frac{\mathrm{d} \theta_{\mathrm{e}}}{\mathrm{d} z} \cong 0$ in this layer, it does 

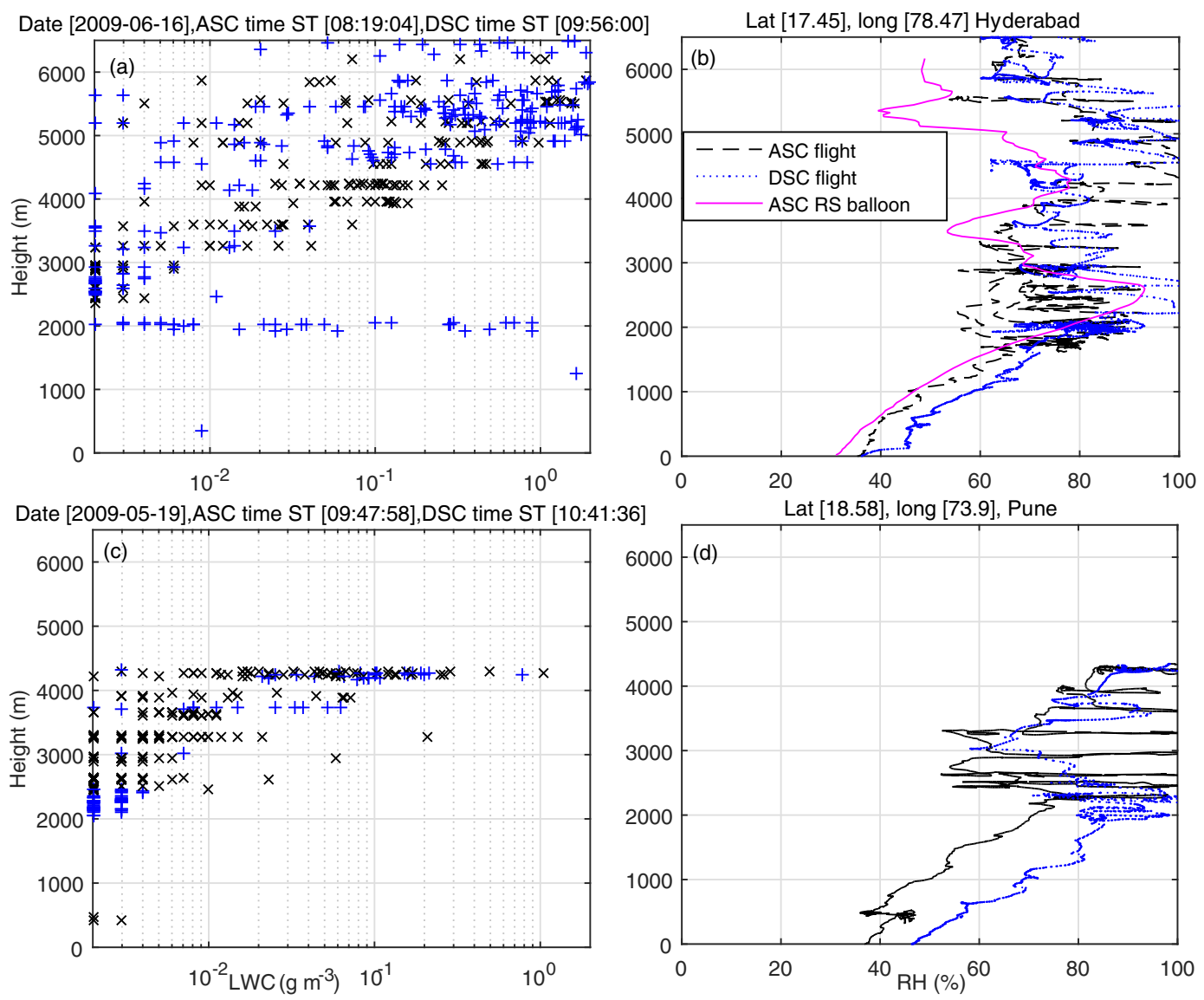

Figure 5. (a) Liquid water content (LWC) and (b) relative humidity (RH) observed over Hyderabad on 16 June 2009. Black and blue colours indicate ascending and descending flights, respectively. An ascending profile of RH using radiosonde observation is shown in magenta. Panels (c) and (d) are the same as (b) and (d) but observed over Pune during 19 May 2009.

not represent the moist layer as $\mathrm{RH}$ is only $\sim 30 \%$. Thus, the layer above the CBL is convectively unstable. The top of this layer is capped by the FWBL in which $\theta, \theta_{\mathrm{v}}$, and $\theta_{\mathrm{es}}$ increase but $\theta_{\mathrm{e}}, \mathrm{RH}, q$, and $N$ decrease more and have a local minimum in $N^{\prime}$. In this case there is no temperature inversion observed at the top of the FWBL (see Supplement Fig. S2f). Thus, from the examples above, it appears that the top of the FWBL is not always marked by the temperature inversion at the altitude of the freezing point.

\subsection{Evolution of the CBL in the presence of clouds}

Before evaluating the ABL behaviour in the presence of clouds, we first document the criteria to identify the cloud layer using the RH profile and its validation with the LWC vertical profile as shown in Fig. 5. Figure 5 shows the LWC and RH profiles using aircraft in situ instruments observed over Hyderabad on 16 June 2009 and Pune on 19 May 2009. The profile of the RH using radiosonde over Hyderabad is also shown. The cloud is observed at a height of about $2.1-2.7 \mathrm{~km}$ at the boundary layer, with $\mathrm{RH}$ values ranging between $83 \%$ and $93 \%$. At this level the airborne $\mathrm{RH}$ is $\sim 85 \%$ and $\mathrm{LWC}$ is found to be about $\sim 0.003-0.006 \mathrm{~g} \mathrm{~m}^{-3}$. The smaller difference between equivalent potential temperature and saturated equivalent potential temperature also indicates the presence of clouds, which will be discussed later in Sect. 3.4. The airborne measurements of RH and LWC indicate the presence of the cloud layer between 2.0 and $6.0 \mathrm{~km}$. The trajectories of the flight and balloon show that the sampling region of the flight is mostly about $50 \mathrm{~km}$ away from the radiosonde sampling region (see Supplement Fig. S5). The clouds at $2.5 \mathrm{~km}$ detected by both radiosonde and aircraft observation appear to have large spatial coverage. Note that the both flight observation $(\sim 13: 30-15: 30$ IST $)$ and radiosonde observation $(\sim 14: 00$ IST) are taken at about the same time. Over Pune, LWC $>0$ and $\mathrm{RH}>83 \%$, indicating cloud layers between 2.0 and $4.0 \mathrm{~km}$. However, in several cases we have observed that the LWC $>0$ even when $\mathrm{RH}>50 \%$ (Supplement Fig. S6). We have calculated the frequency of occurrence of the LWC $>0$ vs. RH in the interval $5 \%$ bins (of RH; Supplement Fig. S6), which shows that although the most of the clouds occur with $\mathrm{RH}>80 \%$ there are cases when clouds occur even with $\mathrm{RH}>50 \%$. How- 
ever, in the present study when RH $>50 \%$ the difference between saturated equivalent potential temperature and equivalent potential temperature is larger and hence indicates unsaturated air (Fig. 4). Thus, we have followed Wang and Rassow (1995) to obtain the cloud layer considering $\mathrm{RH}>83 \%$ for $\sim 1.0 \mathrm{~km}$, along with the condition that the difference between $\theta_{\mathrm{e}}$ and $\theta_{\mathrm{es}}$ is small (Ramana et al., 2004).

Figure 6 shows the vertical profiles of $\theta, \theta_{\mathrm{v}}, \theta_{\mathrm{e}}, \theta_{\mathrm{es}}, q$, $N$, and $N^{\prime}$ (gradient of $N$ ) observed at 13:26 IST on 4 July, 13:40 IST on 12 August, 16:45 IST on 22 September, and 12:22 IST on 6 September, respectively, over Bangalore, Hyderabad, Pune, and Guwahati up to $6 \mathrm{~km}$ above the surface during the Indian summer monsoon season in 2009 in the presence of a cloud layer. In all these profiles the CBL is identified based on any one variable either as the maximum gradient in the temperature variables or moisture variables (Mehta et al., 2017). An absence of an inversion layer near the boundary layer top in the presence of the cloud layer can be seen. Note that the identification of the boundary layer top becomes difficult in the presence of deep clouds (Stull, 1988; Garratt, 1992). At all these stations $\theta_{\mathrm{e}}$ and $\theta_{\mathrm{es}}$ values are nearly constant and the difference between them is nearly zero in the cloud layer, indicated by the shaded box. These grey boxes represent an altitude region where $\mathrm{RH}$ is greater than $90 \%$, indicating the deep convective clouds (Wang and Rassow, 1995; Wang et al., 1999). In these cases, the FWBL is not observed, unlike the cases shown in Fig. 4a-f. It is interesting to note that the $N^{\prime}$ fluctuations are almost steady in the vicinity of the cloud layers. For the cases when the cloud layer occurs above the CBL, it is well identified from $N^{\prime}$ profiles observed over Bangalore (Fig. 6a) and Pune (Fig. 6c). However, for cases when the cloud layer extends into the CBL, identification of the CBL from $N^{\prime}$ profiles becomes difficult as there is no well-defined minima observed over Hyderabad (Fig. 6b) and Guwahati (Fig. 6d). In these cases, the CBL is identified using the relative behaviour of $\theta_{\mathrm{e}}, \theta_{\mathrm{es}}$, and $q$.

\subsection{Observation of the cloud-top boundary layer (CTBL)}

Figure 7 shows the vertical profiles of $\theta, \theta_{\mathrm{v}}, \theta_{\mathrm{e}}, \theta_{\mathrm{es}}, q, N$, and $N^{\prime}$ up to $6 \mathrm{~km}$ above the surface in the presence of the CTBL where clouds are observed beneath the capping inversion. Figure 7a shows the typical evolution of the CTBL in which vertical gradients of $\theta$ and $\theta_{\mathrm{v}}$ are nearly zero up to $\sim 1.0 \mathrm{~km}$ (adiabatically stratified) over Bangalore at 13:30 IST during 5 July 2009. The stratocumulus cloud is trapped underneath the inversion base (at $\sim 1.65 \mathrm{~km}$ ) and is marked by the shaded box with a RH exceeding $83 \%$ (Wang et al., 1999). Within the cloud layer, the difference between $\theta_{\mathrm{e}}$ and $\theta_{\mathrm{es}}$ is very small. The cloud base $(\sim 1.0 \mathrm{~km})$ is interestingly also marked by the kink in $q$ and a local minimum in $N^{\prime}$ profiles that shows a change in the temperature lapse rate from a nearly dry-adiabatic $\left(\sim 9.2 \mathrm{~K} \mathrm{~km}^{-1}\right.$, a well-mixed ABL $)$ to
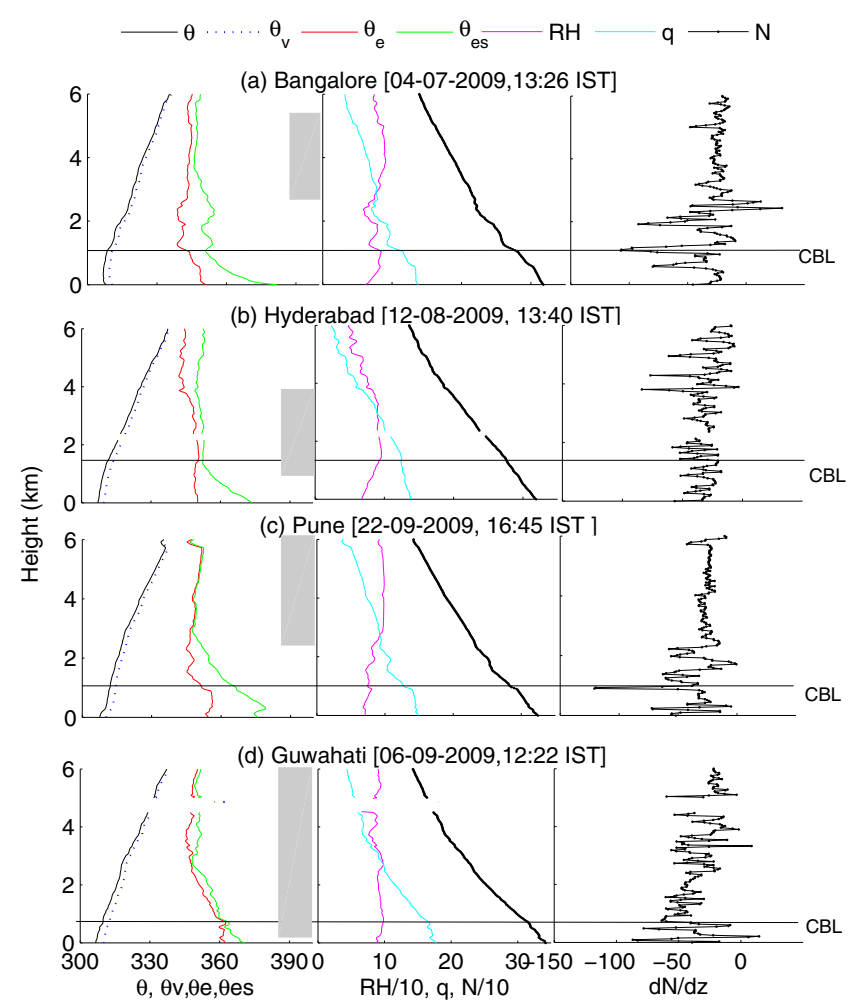

Figure 6. Same as Fig. 4 but observed over (a) Bangalore on 4 July 2009, (b) Hyderabad on 12 August 2009, (c) Pune on 22 September 2009, and (d) Guwahati on 6 June 2009, indicating the CBL and the cloud layer. The grey rectangular box indicates the cloud layer representing the location with $\mathrm{RH}>83 \%$.

a saturated-adiabatic lapse rate $\left(\sim 4.8 \mathrm{~K} \mathrm{~km}^{-1}\right.$; see Supplement Fig. S3a) inside the cloud. The stratocumulus cloud observed here is coupled with the mixed layer below and indicates a fully coupled system due to turbulent mixing (Garratt, 1994). The LCL $(\sim 1.0 \mathrm{~km})$ coincided with the cloud base. The TBB $(\sim 282 \mathrm{~K})$ and the corresponding BTH $(\sim 2.75 \mathrm{~km})$ do not represent the top of the CTBL and interestingly coincided with kink in the $N$. A mid-level cloud can also be seen with a cloud base marked by a kink in $q$ and a local minimum in $N^{\prime}$ at $4.35 \mathrm{~km}$, with a small difference in $\theta_{\mathrm{e}}$ and $\theta_{\mathrm{es}}$ inside the cloud layer.

Figure $7 \mathrm{~b}$ shows the typical evolution of the CTBL through which vertical gradients of $\theta$ and $\theta_{\mathrm{v}}$ are nearly zero up to $\sim 2.0 \mathrm{~km}$ (adiabatically stratified) over Hyderabad at 14:80 IST during 16 June 2009. The cloud forms at the top of the mixing layer and within the EZ. The stratocumulus cloud with a width of $\sim 0.3 \mathrm{~km}$ represents the coupled system and it is formed due to turbulence generated by surface forcings. The LCL $(\sim 1.14 \mathrm{~km})$ forms below the cloud base. However, the TBB $(\sim 292 \mathrm{~K})$ and the corresponding BTH $(\sim 2.15 \mathrm{~km})$ nearly represent the top of the CTBL.

Figure $7 \mathrm{c}$ shows the typical evolution of the CBL through which vertical gradients of $\theta$ and $\theta_{\mathrm{v}}$ are nearly zero up to 

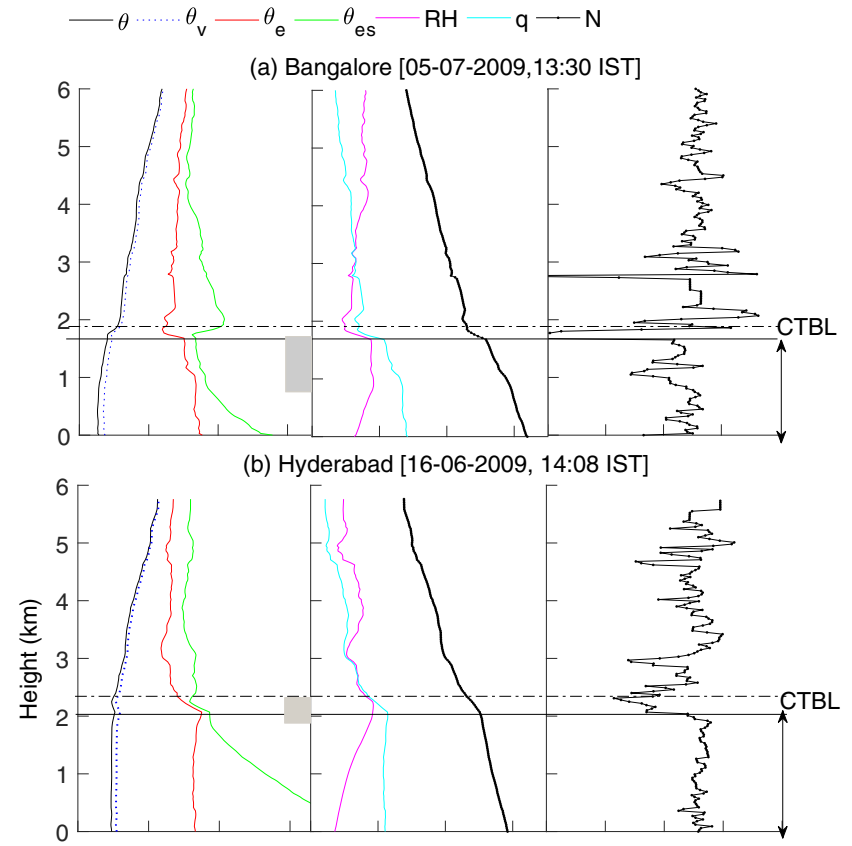

(c) Pune [19-09-2009,17:14 IST]

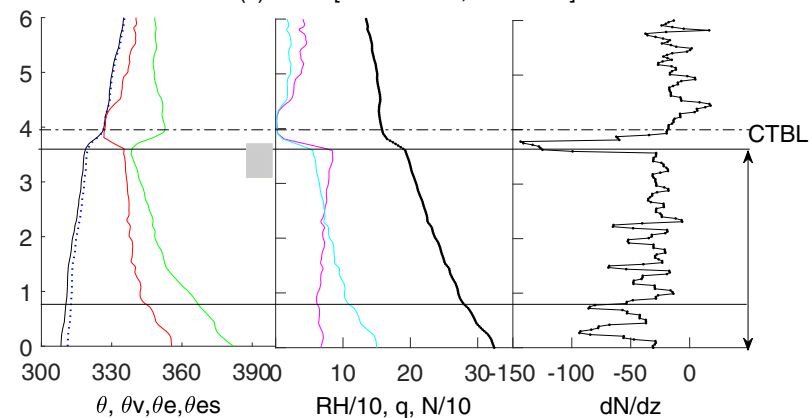

Figure 7. Same as Fig. 4 but observed over (a) Bangalore on 5 July 2009, (b) Hyderabad on 16 June 2009, and (c) Pune on 19 September 2009, indicating the CTBL. The grey rectangular box indicates the cloud layer representing $\mathrm{RH}>83 \%$.

$\sim 0.7 \mathrm{~km}$ over Pune at 17:14 IST during 19 September 2009. However, there is no well-defined inversion layer at the top of the CBL. The stratocumulus cloud is trapped underneath the inversion base (at $\sim 3.6 \mathrm{~km}$ ) and is marked by the shaded box with RH exceeding $83 \%$. Within the cloud layer, the difference between $\theta_{\mathrm{e}}$ and $\theta_{\mathrm{es}}$ is very small. The stratocumulus cloud with a width of $\sim 0.3 \mathrm{~km}$ represents the de-coupled system and it has not formed due to turbulence generated by surface forcings. This cloud would have formed due to trade wind inversion. In this case, the LCL $(\sim 1.0 \mathrm{~km})$ and the BTH $(\sim 0.9 \mathrm{~km})$ corresponding to TBB $(\sim 292 \mathrm{~K})$ are found to be far below the cloud base.

\subsection{Day-to-day variation in the CBL}

Figure 8 shows the time series of the day-to-day variation in the CBL height, EZ, FWBL top and bottom whenever ob-
Table 2. Mean, SD, and coefficient of variation of the CBL at each station and for clear and cloudy conditions.

\begin{tabular}{lrrr}
\hline & Mean $(\mathrm{km})$ & $\mathrm{SD}(\mathrm{km})$ & $\mathrm{CV}(\%)$ \\
\hline Bangalore & 1.09 & 0.45 & 2.43 \\
Hyderabad & 0.937 & 0.4 & 2.34 \\
Pune & 0.643 & 0.29 & 2.24 \\
Guwahati & 1.074 & 0.29 & 3.74 \\
Bareilly & 1.02 & 0.42 & 2.42 \\
Pathankot & 1.704 & 0.81 & 2.1 \\
\hline Overall & & & \\
\hline Clear & 1.08 & 0.55 & 1.97 \\
Cloudy & 0.83 & 0.26 & 3.18 \\
\hline
\end{tabular}

served, LCL height, and BTH over the six stations during different periods in the Indian summer monsoon season of the year 2009 as listed in Table 1 . We have only one sounding per day launched mostly between 12:00 and 14:00 IST, except a few that were launched at 11:00, 16:00, and 17:00 IST. Thus, Fig. 8 represents the day-to-day variation after noontime. Figure 8a shows the CBL variations for 3 days during 2-4 June 2009 and 8 days during 28 June-5 July 2009 in the summer monsoon season over Bangalore. At this station, all radiosondes are launched at 12:00-14:00 IST except one at 16:00 IST. It is observed that the CBL height varies between 1.0 and $2.0 \mathrm{~km}$. The mean, standard deviation (SD), and coefficient of variation (CV) of the CBL is listed in the Table 2. The mean and SD of the CBL height over Bangalore is $0.93 \pm 0.4 \mathrm{~km}$. In all the 11 cases, the CBL over Bangalore is well defined and was identified using all the moisture and temperature variables. Thus, the EZ has been observed for all the cases over Bangalore. Out of 11 cases, five cases represent the top of the CTBL, and two cases represent when mid-level cloud layers were observed. Cloud layers are identified based on the $\mathrm{RH}>83 \%$ criterion (see Supplement Fig. S4a). It is observed that the growth of the vertical extent of the cloud is $\sim 0.09 \mathrm{~km}$ on 29 June 2009 to $\sim 0.5 \mathrm{~km}$ on 2 July 2009 , with a monotonic increase in the CBL height. On 3 July 2009, the CBL descended by $0.8 \mathrm{~km}$ with the formation of the cloud layer at $\sim 4.0-6.0 \mathrm{~km}$. The next day on 4 July 2009, the CBL remained at the height of $\sim 1.0 \mathrm{~km}$ with a cloud layer at $\sim 3.5-5.0 \mathrm{~km}$. The CBL height then increased by $0.7 \mathrm{~km}$ and is observed at $\sim 1.74 \mathrm{~km}$ with the formation of stratocumulus cloud beneath the CBL along with mid-level cloud on 5 July 2009. Five cases show that the FWBL are observed far above the CBL in the altitude range of $\sim 2-5 \mathrm{~km}$. The FWBL is determined using the relative variance in the $\theta_{\mathrm{e}}$ and $\theta_{\mathrm{es}}$. It can be seen that the FWBL increases with an increase in the CBL. Over Bangalore, BTH is found to be at a lower height than the CBL, indicating a clear sky, or mostly fair-weather conditions. Similarly, LCL occurs just above the CBL for most cases. The LCL represents the base of the CTBL observed on 2 and 5 July 2009. 

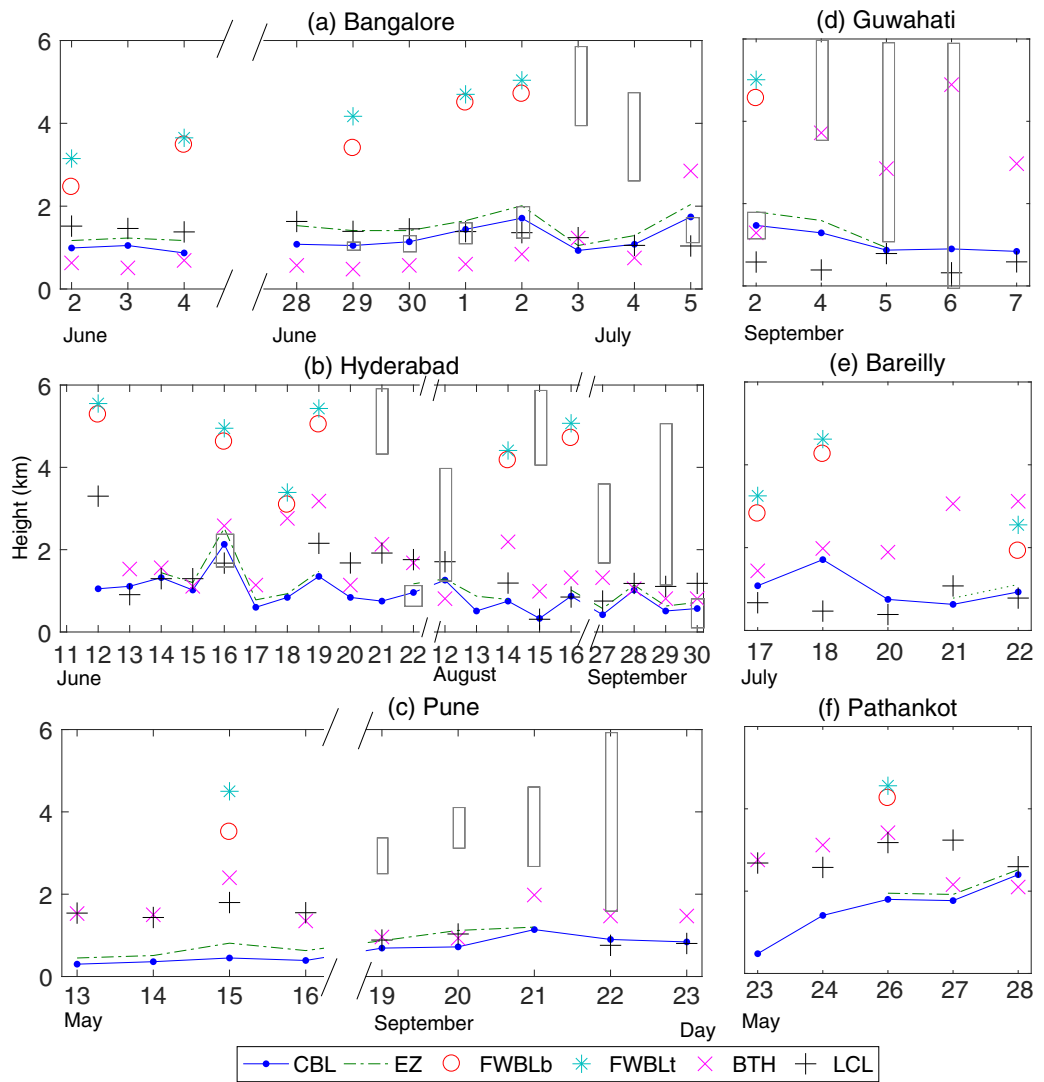

Figure 8. Time series of the CBL, EZ, FWBL $b$, FWBL, LCL height, and the BTH observed over (a) Bangalore, (b) Hyderabad, (c) Pune, (d) Guwahati, (e) Bareilly, and (f) Pathankot during the Indian summer monsoon season as listed in Table 1. The grey rectangular box indicates the cloud layer representing the location with $\mathrm{RH}>83 \%$.

There are two cases when mid-level clouds (3-4 July 2009) are observed, for which the CBL is found to be at a lower level and both the BTH and LCL are found to be near the CBL.

Figure $8 \mathrm{~b}$ shows the CBL variations for 11 days during June (12-22 June), 5 days during August (12-16 August), and 4 days during September (27-30 September) in the summer monsoon season over Hyderabad. At this station, all radiosondes were launched at 12:00-14:00 IST except one at 11:00 IST. It is observed that the day to day variation in the CBL height varies as low as $\sim 0.3 \mathrm{~km}$ to as high as $\sim 2.5 \mathrm{~km}$. The mean and SD of the CBL height over Hyderabad is $0.93 \pm 0.4 \mathrm{~km}$ (Table 2). Note that the monsoon onset date is 21 June over Hyderabad during 2009. The CBL is found to be higher, warmer, and drier pre-monsoon (11-21 June 2009) when compared to during the monsoon (22 June, 12-16 August, 28-30 September) months (Bera et al., 2016). Out of 20 cases, in seven cases the CBL over Hyderabad is well defined, for which the EZ is observed and identified using both the moisture and temperature variables. The other 11 cases are identified using the moisture, temperature, or refractivity gradient. For these cases the EZ is not formed. Out of 20 days, five cases represent the top of the CTBL and in two cases mid-level cloud layers are observed. It is seen that the CBL height increases by $\sim 1.0 \mathrm{~km}$ and $0.2 \mathrm{~km}$ from the previous day with the development of the cloud beneath the inversion as evident on 16 June 2009 and 22 June 2009, respectively. On 30 September 2009, cloud has formed within the entire boundary layer topped with a weak inversion layer. In this case the CBL does not increase and is different from the earlier two cases in which they have well-defined EZ. As mentioned earlier (Fig. 8a), the increase in CBL depth depends upon the vertical extent of the cloud. On 21 June, 12 and 15 August, and 27 and 29 September 2009 mid-level clouds are observed at $\sim 4.5-6.0,1.0-4.0,4.0-6.0,1.8-3.3$, and $1.0-0.75 \mathrm{~km}$ above the CBL, respectively (see Supplement Fig. S4b). During these occasions the CBL forms at lower heights when compared to clear-sky days. In total there were 6 days, 12, 16, 18, and 19 June 2009 and 14 and $16 \mathrm{Au}-$ gust 2009, when the FWBL formed at an altitude of 5.3, 4.6, 3.1, 5.0, 4.4, and $4.7 \mathrm{~km}$, respectively. Over Hyderabad BTH mostly occurred near the CBL or just above it, with the LCL below them. The LCL represents the cloud base and the BTH is the cloud top of the CTBL observed on 16 June 2009.

Figure $8 \mathrm{c}$ shows the CBL variations for 4 days during May (13-22 May 2009) in the pre-monsoon season and 5 days 
during September (19-23 September 2009) in the summer monsoon season over Pune. At this station, all radiosondes in May were launched at $\sim$ 11:00 IST while during September they were launched at $\sim$ 17:00 IST. Thus, over Pune, the day-to-day variability during May and September is separately discussed. It is observed that the day-to-day variation in the CBL height is very small and the CBL varies between 0.3 and $1.2 \mathrm{~km}$ in both the pre- and post-monsoon seasons (Table 2). During May 2009 (4 days), the CBL was well defined and was identified using both the moisture and temperature variables, while during September (5 days) the CBL was identified using the moisture, temperature, or refractivity gradient. Out of 9 days, two cases with mid-level cloud layers were observed (see Supplement Fig. S4c). On 15 May 2009 a CTBL with decoupled stratocumulus cloud is observed as mentioned earlier in Fig. $6 \mathrm{c}$ and it is not considered as mid-level cloud. On 21-22 September 2009 midlevel clouds are observed at altitude ranges of $\sim 2.3-4.6$ and 1.8-6.0 km above the CBL, respectively. In total, there were 2 days, 15 May 2009 and 21 September 2009, when FWBLs formed at altitudes of $\sim 3.5$ and $\sim 4.0 \mathrm{~km}$, respectively. Over Pune, BTH mostly occurred near the CBL or just above it with LCLs below them.

Figure $8 \mathrm{~d}$ shows the CBL variations for 5 days during September (2-7 September 2009) in the summer monsoon season over Guwahati, observed mostly during cloudy conditions with cloud in various altitude ranges. At this station, all radiosondes were launched between $\sim$ 12:00 and 15:00 IST. CBL height varies from 0.78 to $1.7 \mathrm{~km}$ as shown in Table 2 . Out of 5 days, mid-level clouds were observed for 3 days during 4-6 September 2009 at altitude ranges of $~ 3.7-5.5,1.5-$ 6.0 , and $0-6.0 \mathrm{~km}$, respectively. The FWBL is only observed at $\sim 4.5 \mathrm{~km}$ for 1 day on 2 September when the atmosphere was relatively clear. Over Guwahati, the LCL forms well below the CBL. The BTH is found to be above the CBL and indicates cloudy conditions. On 7 September, though BTH occurred at $\sim 3.0 \mathrm{~km}$ indicating cloudiness, the RH never exceeded $77 \%$ (see Supplement Fig. S4d).

Figure $8 \mathrm{e}$ shows the CBL variations for 5 days during July (17-22 July) in the summer monsoon season 2009 over Bareilly. At this station, all radiosondes were launched between $\sim 14: 00$ and 16:00 IST. The TBB (281-288 K) and $\mathrm{RH} \approx 80 \%$ indicate the presence of low-level cloud (see Supplement Fig. S4e). The CBL heights over Bareilly are identified based on the local minimum in the $N^{\prime}$ profile. CBL height varies from 0.6 to $1.8 \mathrm{~km}$ as shown in Table 2 . The FWBLs are observed at $\sim 2.8,4.2$, and $2.2 \mathrm{~km}$ on $17-$ 20 July 2009, respectively. Over Bareilly, the LCL mostly occurs below the CBL, and BTH either occurs near or above the CBL.

Figure $8 \mathrm{f}$ shows the CBL variations for 5 days during May (23-28 May) in the pre-monsoon season in 2009 over Pathankot. At this station all radiosondes were launched between $\sim$ 13:00 and 15:00 IST. These observations are made during clear-sky conditions $(\mathrm{RH}<30 \%$; see Supplement
Fig. S4f). Supplement Fig. S4f shows that there is a large variation in RH at $4.0 \mathrm{~km}$ on 27 May 2009, which indicates a layering structure associated with horizontal advection rather than a moisture source from the boundary layer, which was dry (Prabha et al., 2012). However, TBB shows that cloud-top height at $\sim 2-3 \mathrm{~km}$ closely matches LCL height, but occurrence of these clouds is not indicated by RH observations. This disparity in cloud observation based on the BTH and RH is difficult to explain here. Over this site, the CBL varies from 0.4 to $\sim 2.0 \mathrm{~km}$ within 5 days. The FWBL is observed to be at $4.5 \mathrm{~km}$ on 26 May 2009 , consistent with the elevated layer reported by Prabha et al. (2012). It is observed that the overall CBL is higher during clearsky $(1.08 \pm 0.55 \mathrm{~km})$ conditions when compared to cloudy $(0.83 \pm 0.26 \mathrm{~km})$ conditions. The CV indicates that the CBL height is more variable during cloudy $(3.18 \%)$ days when compared to clear-sky (1.97\%) days. It is also evident from Table 2 that the CBL height over Guwahati (mostly cloudy cases) is more variable than at the rest of the stations.

\subsection{Correlation analysis}

In order to examine the influence of the surface forcing and the effect of clouds on the evolution of the CBL, correlation between the CBL heights and the surface temperature, the relative humidity, LCL height, and BTH is obtained, as shown in Fig. 9. We have observed 17 cases when the clouds had a vertical extent of more than $1.0 \mathrm{~km}$ (based on $\mathrm{RH}>83 \%$ criterion), during which the CBL is found to be lower than when compared to clear-sky conditions. Here, we have not considered the cases of cloud occurring just below the CBL with limited vertical extent $(<0.5 \mathrm{~km}$; e.g. CTBL cases), as during these cases the CBL height generally increases (Fig. 7). It is evident from Fig. 9a and b that during cloudy days the surface temperature is generally lower $(<300 \mathrm{~K})$ and $\mathrm{RH}$ at the surface is generally higher (>50\%), respectively, as expected. The correlation between the surface temperature and the CBL height indicates that with the increase in the surface temperature, CBL height increases and vice versa. This, however, does not hold in all cases and hence we observe a large scatter (Fig. 8a). During cloudy days, $\mathrm{CBL}$ height also increases with an increase in the surface temperature, but it remains lower than that of the rest of the observations, indicating the effect from both the surface temperature and clouds. They play a prominent role in the evolution of the CBL during cloudy days. In general, CBL decreases with the increase in surface moisture (Fig. 9b). That is, during clear-sky conditions the CBL is higher than on cloudy days. However, surface moisture content does not always determine the growth of the CBL as there are cases in which the CBL is higher during totally moist conditions when compared to semi-moist conditions. During cloudy days, as mentioned earlier, the CBL occurs at a lower height, and interestingly LCL also mostly occurs at lower heights (Fig. 9c). It is well known that the LCL height 

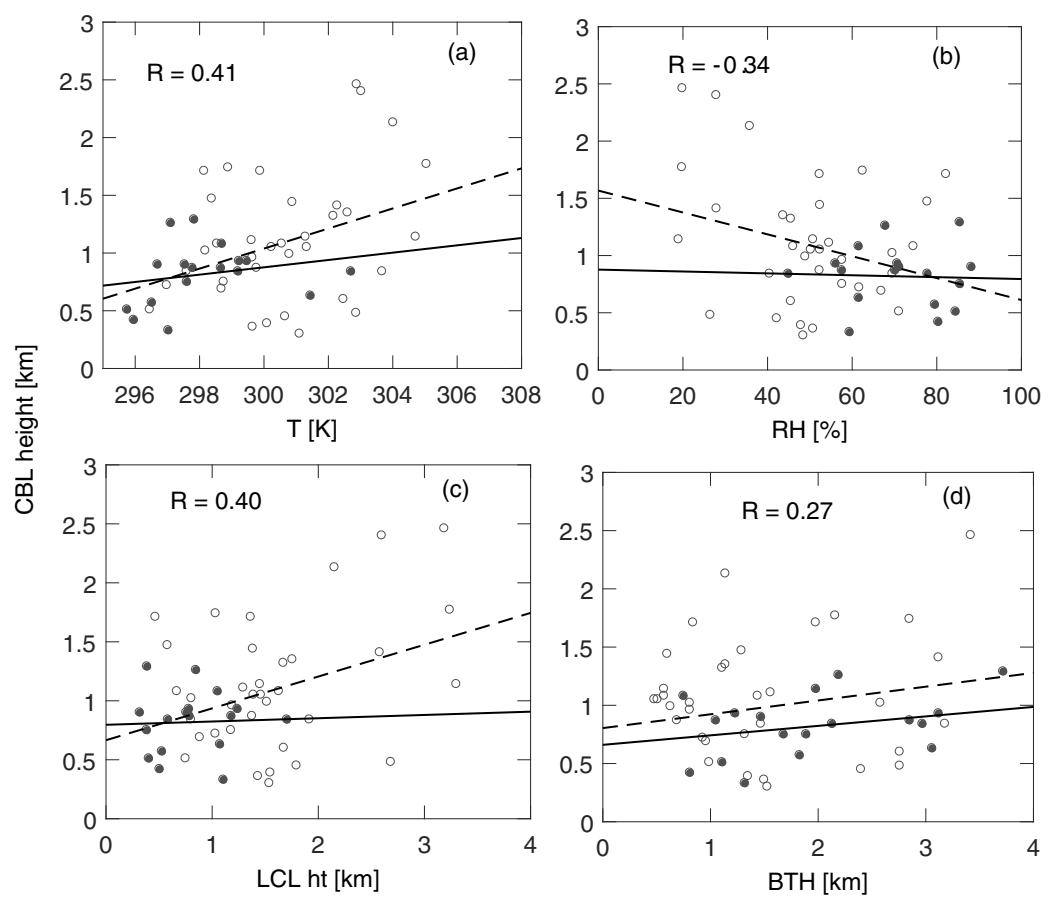

Figure 9. Scatter plot between the CBL height, (a) surface temperature, (b) relative humidity, (c) LCL height, and (d) BTH observed over six stations. Open circles indicate the cases during clear-sky conditions, which also include FWBL and CTBL cases. Solid circles indicate cloudy conditions based on $\mathrm{RH}>83 \%$ criteria with cloud having a vertical extent of more than $1 \mathrm{~km}$. Dashed and solid lines represent the regression lines for clear-sky and cloudy conditions, respectively.

and the CBL are not always related (Mehta et al., 2017). However, there are cases when CBL increases with the increase in the LCL and vice versa. When LCL occurs below the CBL the presence of thin clouds within the CBL is possibly indicated (Balaji et al., 2017). Similarly, overall CBL height and BTH are not always related. However, for the majority of the cases the CBL height remains lower during cloudy conditions (based on $\mathrm{RH}>83 \%$ for about more than $1.0 \mathrm{~km}$ ) when BTH has increased. The cloudy cases identified using the RH criterion do not always correspond to the cloud-top temperature using satellite data, which needs to be investigated in detail.

\subsection{Comparison between CBL heights obtained using CALIPSO and radiosonde}

As we have a good number of radiosonde launchings about the timings of the CALIPSO passes over these stations, an effort has also been made to compare the CBL height obtained from the backscatter coefficient and radiosonde temperature and moisture profiles. Six simultaneous observations of the radiosonde and CALIPSO are listed in Table 1. Figure 10 shows the comparison of the CBL height obtained from aerosol backscatter profiles using CALIPSO observation and refractivity profiles derived using radiosonde observation above mean sea level. The corresponding thermodynamic profiles of $\theta, \theta_{\mathrm{v}}, \theta_{\mathrm{e}}, \theta_{\mathrm{es}}, q, N$, and $N^{\prime}$ over the ground level of these sites are shown in Supplement Fig. S7. Typical plots of the backscattering ratio and $N^{\prime}$ observed over Bangalore on 29 June 2009, Hyderabad on 15 June 2009, Guwahati on 4 September 2009, and Pathankot on 23 May 2009 are shown in Fig. 10a-d, respectively. Over Bangalore, CALIPSO passes about $1.5^{\circ}$ west of the radiosonde launch site. The surface elevation around Bangalore is $\sim 1.0 \mathrm{~km}$ a.m.s.l. The CBL is well marked as a strong peak in the $\log _{10} \beta$ as well as in mean $\log _{10} \beta$ averaged over $1^{\circ}$ latitude centred at Bangalore. The CBL height identified from the mean $\log _{10} \beta$ profile is $\sim 2.5 \mathrm{~km}$ a.m.s.l. It is $\sim 0.5 \mathrm{~km}$ higher than the CBL height identified using the $N^{\prime}$ profile (Fig. 10a, third panel). However, the CBL heights from both $\log _{10} \beta$ and $N^{\prime}$ match well at the closest proximity to Bangalore $\left(12.98^{\circ} \mathrm{N}\right)$. It is observed that the comparison between CBL heights is better when it is calculated from the profile with the closest proximity rather than from the averaged profile over $1^{\circ}$ latitude. As the CBL height varies between 2.0 and $2.5 \mathrm{~km}$, comparison of the CBL using radiosonde and CALIPSO may not be suitable using mean $\log _{10} \beta$ averaged over $1^{\circ}$, which needs to be taken into account. It also indicates that the CBL has high spatial variability. Over Hyderabad $\left(174.48^{\circ} \mathrm{N}\right)$, CALIPSO passes about $0.5^{\circ}$ west of the radiosonde launch site. Using CALIPSO, the CBL is poorly defined at $\sim 3.0 \mathrm{~km}$ a.m.s.l., where a local minimum in $N^{\prime}$ is also present. However, as the radiosonde data are not available below $1.2 \mathrm{~km}$ a.m.s.l. (Fig. 10b, third panel), 

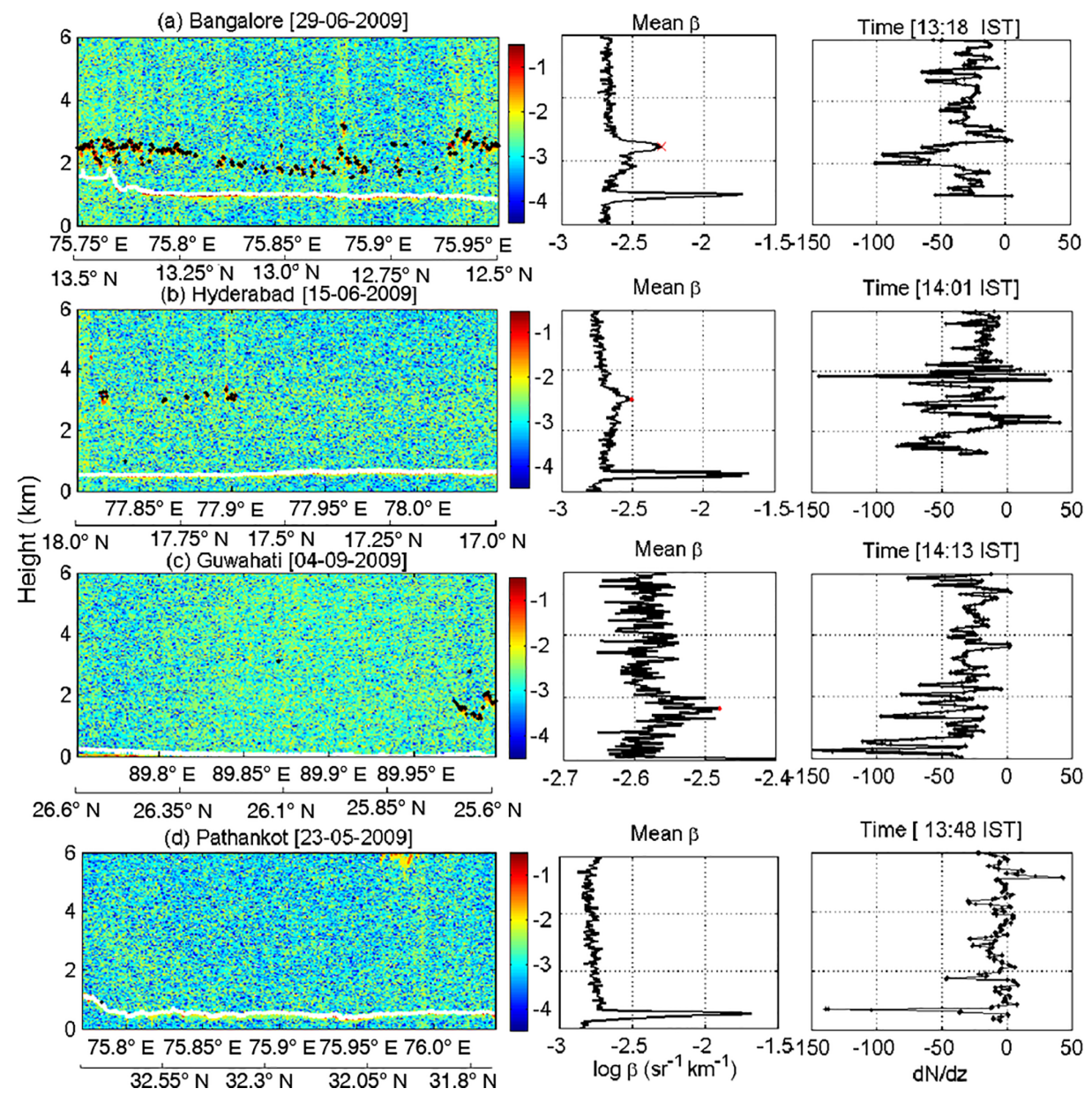

Figure 10. Typical comparison of the CBL obtained using the CALIPSO backscattering coefficients collected within $\pm 0.5^{\circ}$ latitude centred at each radiosonde site (first column panels). Mean backscattering coefficients over the entire $1^{\circ}$ latitude track (second column panels) and radiosonde refractivity profiles (third column panels) observed over (a) Bangalore on 29 June 2009, (b) Hyderabad on 15 June 2009 , (c) Guwahati on 4 September 2009, and (d) Pathankot on 23 May 2009.

it is a little inconvenient to define the CBL height in this case. For this case, the meteorological parameters over Hyderabad and Bangalore appear nearly similar and thus we identify the CBL height over Hyderabad as $\sim 1.5 \mathrm{~km}$ a.m.s.1. ( $\sim 1.0 \mathrm{~km}$ a.g.l.) (see Supplement Fig. S7a and b). Similarly, over Guwahati $\left(26.10^{\circ} \mathrm{N}\right)$, where CALIPSO passes about $1.5^{\circ}$ east of the radiosonde launch site, the CBL is poorly defined from both of the independent observations. In this case, as cloud layer is seen above $\sim 4.0 \mathrm{~km}$, the lidar signal may have become weak and hence we are unable to detect the CBL height. In general, the detection of the ABL becomes difficult during cloudy conditions. Over Pathankot $\left(32.26^{\circ} \mathrm{N}\right.$, $75.63^{\circ} \mathrm{E}$ ) CALIPSO passes about $0.5^{\circ}$ west of launching site over the Siwalik Hills. Using radiosonde, we can see that the CBL (as a mixed layer) formed at a height of $\sim 0.4 \mathrm{~km}$ a.g.l. and nearly the same level of the top of the Siwalik Hills as indicated by the height of the topography using CALIPSO data (Fig. 10d). Over the hills, the CBL is not detectable in the backscattering ratio profile.

\section{Discussion and conclusions}

An effort has been made to collect the high-resolution radiosonde data during 11:00-17:00 IST over the six stations in the Indian monsoon region during the period from May to September (covering the period from onset to withdrawal) of the Indian summer monsoon in 2009. These stations cover a large geographical region, ranging from latitude $\sim 13$ to $32^{\circ} \mathrm{N}$ to longitude 73 to $92^{\circ} \mathrm{E}$. Using routine radiosonde (at 05:30 and 17:30 IST), the CBL has been extensively studied (Seidel et al., 2010). The thermodynamic structure of the CBL is still poorly known, especially over land in the Indian monsoon region (Parasnis and Goyal, 1990). Over the adjoining sea, extensive studies have been conducted to understand the thermodynamic structure of the marine ABL (Subrahamanyam and Ramachandran, 2003; Ramana et al., 2004; Alappattu and Kunhikrishnan, 2010). Since routine radiosonde basically covers the morning (05:30 IST) 
and evening (17:30 IST) transition phase, the well-developed CBL cannot be studied using these observations.

The CBL is not only driven by surface forcings but is also affected by the processes above the CBL, such as the presence of the clouds, horizontal advection of the air masses, etc. One of the important thermodynamic structures is the prevalence of fair-weather clouds, especially during the monsoon season, over the Indian region. These FWBLs are characterized by a sharp decrease in the humidity (RH and $q$ ) and $\theta_{\mathrm{v}}$ and an increase in the $\theta_{\mathrm{es}}$, similar to trade wind inversions over the ocean (Subrahamanyam and Ramachandran, 2003; Ramana et al., 2004; Alappattu and Kunhikrishnan, 2010). We have shown that the FWBL can also be identified by the local minimum in the $N^{\prime}$. Note that these FWBLs do not always represent the mid-level temperature inversions or temperature inversion at the freezing point (Johnson et al., 1996). At the FWBL, there is an increase in the temperature but they need not represent the temperature inversion always and hence for most of the cases the local minimum in the $N^{\prime}$ is mainly caused by the sharp decrease in humidity. As the occurrence of the FWBL is small (19 out 57 cases), statistical analysis of data is not possible. However, in general, it is observed that the FWBL increases with an increase in the CBL and vice versa.

We have examined the thermodynamic structure of the CBL evolution during the cases of dry and cloudy atmosphere. It is known that the CBL does not always represent the well-mixed layer and hence is generally referred to as the "mixing layer" (Seibert et al., 2000). During clear-sky condition, when the CBL is well mixed both thermodynamic profiles as well as the $N^{\prime}$ profiles identify the CBL height well, with some exception. However, when the CBL is not adiabatically stratified, its identification from the thermodynamic profiles becomes difficult. For these stably stratified cases the top of the CBL is found to be well marked by $N^{\prime}$. Hence $N^{\prime}$ serves as better indicator of the CBL when compared to $\theta_{\mathrm{v}}$ and $q$ (Basha and Ratnam, 2009) because it takes into account the variation in temperature and moisture together, however, not always especially during cloudy conditions. Just above the CBL, the moisture generally decreases by 6 times its value at the CBL (Mehta et al., 2017). However, on some occasions if there is a sharp increase in the moisture just above the CBL (which indicates either presence of clouds or occurrence of horizontal advection), the CBL identified using the local minimum in $N^{\prime}$ will be higher than that obtained using local maxima in the temperature gradient.

Low-level clouds (mainly stratus or stratocumulus clouds) occur either below, near, or above the CBL. In most of the cases the cloud layers $(\mathrm{RH}>83 \%)$ are represented by a relatively high BTH value, whereas the BTH values are low for the cases of the clear-sky conditions with some disparity. On some occasions when RH is between about 60 and $80 \%$ as well as on other occasions during dry atmosphere (RH $\sim 20-30 \%$ ), BTH is found to be higher. The disparity in identification of the cloud layer from the RH-based method and BTH is not possible to explain here with the limited dataset and will be carried out using a more extensive dataset in a separate study. In this study, we have used $\mathrm{RH}>83 \%$ criteria to mark the presence of the cloud layer. Similar to our previous findings (Mehta et al., 2017), we observed that whenever cloud occurs above the CBL, it is found to be at a lower height when compared to clear-sky days. During cloudy (clouds occurring above the CBL) days, the surface temperature is also lower when compared to clearsky days. This indicates that the convective turbulence becomes weak during cloudy days and hence CBL forms at a lower height when compared to clear-sky conditions. However, when the CTBL occurs, the CBL is found to be higher when compared to other days. The CTBL is generally coupled to the turbulent mixing (Garratt, 1992) and hence the CBL top increases with an increase in the surface forcings. Finally, the typical comparison between the CBL evolutions using CALIPSO and radiosonde is evaluated. The comparison of the CBL depends upon how closely CALIPSO passes to the radiosonde launching site. For the well-defined case, the CBL tops identified using CALIPSO at the closest proximity to the radiosonde launching sites match well.

The following are the main findings on the thermodynamic structure of the CBL:

1. $N^{\prime}$ serves as a better indicator of the CBL when compared to $\theta_{\mathrm{v}}$ and $q$ but not always, especially during cloudy conditions. Within cloud, $N^{\prime}$ generally remains steady. However, at the top and bottom of the CTBL, the magnitude of the minimum $N^{\prime}$ becomes comparatively larger and is well detected as a minimum in $N^{\prime}$. The top of the FWBL is also marked by a local minimum $N^{\prime}$. However, $N^{\prime}$ at either the CBL or FWBL is not always marked by the temperature inversion.

2. The CBL varies between $\sim 0.4$ and $2.5 \mathrm{~km}$ a.g.l. over the different stations in the Indian monsoon region. The CBL shows large spatial and temporal variations. The occurrence of the clouds at various levels plays an important role in the day-to-day variation in the CBL height. It is observed that the occurrence of the cloud at the boundary layer (i.e. the formation of the CTBL) elevates its height, whereas, the occurrence of the clouds above the CBL generally decreases its height.

3. The CBL during cloudy days is shallow when compared to the clear-sky days. Within monsoon season, both surface temperature and the CBL are lower during cloudy conditions when compared to clear-sky condition. In general, the LCL height and CBL are not always related. Sometimes the LCL occurs below the CBL, sometimes above it. The CBL is randomly related with the BTH.

Data availability. The radiosonde data used in this study can be provided upon request to Sanjay Kumar Mehta (ksan- 
jaym@gmail.com). TBB data can be obtained from the NASA Goddard Earth Sciences Data and Information Services Center (GES DISC). CALIPSO data were obtained from Atmospheric Science Data Center at NASA Langley Research Center. Global 30 arcsec gridded topography data are provided by the National Centre for Environmental Information, USA. CAIPEEX flight data can be obtained upon request from the website http://www.tropmet.res.in/ caipeex/.

\section{The Supplement related to this article is available online at https://doi.org/10.5194/angeo-35-1361-2017- supplement.}

Competing interests. The authors declare that they have no conflict of interest.

Acknowledgements. We thank the TIFR Balloon Facility team for conducting radiosonde observations during the CAIPEEX campaign. We thank IITM Pune for providing the CAIPEEX flight data. We also thank NASA Goddard Earth Sciences Data and Information Services Center and NASA Langley Research Center for providing TBB and CALIPSO data, respectively. We thank SRM HPCC for processing the CALIPSO data. This work is partially supported by network projects under Earth Science and Technology Cell (ESTC) under the Ministry of Earth Sciences (MoES) and the Department of Science and Technology - Science and Engineering Research Board (EMR/2015/000525).

The topical editor, Marc Salzmann, thanks the two anonymous referees for help in evaluating this paper.

\section{References}

Alappattu, D. P. and Kunhikrishnan, P.: Observations of the thermodynamic structure of marine atmospheric boundary layer over Bay of Bengal, Northern Indian Ocean and Arabian Sea during premonsoon period, J. Atmos. Sol.-Terr. Phy., 72, 1318-1326, 2010.

Augstein, E.: The atmospheric boundary layer over the tropical oceans, Meteorology over the Tropical Oceans, 1978, 73-104, 1978.

Balaji, B., Prabha, T. V., Jaya Rao, Y., Kiran, T., Dinesh, G., Chakravarty, K., Sonbawne, S. M., and Rajeevan, M.: Potential of collocated radiometer and wind profiler observations for monsoon studies, Atmos. Res., 194, 17-26, https://doi.org/10.1016/j.atmosres.2017.04.023, 2017.

Basha, G. and Ratnam, M. V.: Identification of atmospheric boundary layer height over a tropical station using high-resolution radiosonde refractivity profiles: comparison with GPS radio occultation measurements, J. Geophys. Res.-Atmos., 114, D16101, https://doi.org/10.1029/2008JD011692, 2009.

Bera, S., Prabha, T. V., and Grabowski, W. W.: Observations of monsoon convective cloud microphysics over India and role of entrainment-mixing, J. Geophys. Res.-Atmos., 121, 9767-9788, https://doi.org/10.1002/2016JD025133, 2016.
Betts, A. K. and Albrecht, B. A.: Conserved variable analysis of the convective boundary layer thermodynamic structure over the tropical oceans, J. Atmos. Sci., 44, 83-99, 1987.

Bianco, L., Djalalova, I., King, C., and Wilczak, J.: Diurnal evolution and annual variability of boundary-layer height and its correlation to other meteorological variables in California's Central Valley, Bound.-Lay. Meteorol., 140, 491-511, 2011.

Bolton, D.: The computation of equivalent potential temperature, Mon. Weather Rev., 108, 1046-1053, 1980.

Chan, K. M. and Wood, R.: The seasonal cycle of planetary boundary layer depth determined using COSMIC radio occultation data, J. Geophys. Res.-Atmos., 118, 12422-12434, https://doi.org/10.1002/2013JD020147, 2013.

Deardorff, J. W.: On the distribution of mean radiative cooling at the top of a stratocumulus - capped mixed layer, Q. J. Roy. Meteor. Soc., 107, 191-202, 1981.

Garrat, J. R.: The Atmospheric Boundary Layer, Cambridge Atmos. Space Sci. Ser., Cambridge Univ. Press, Cambridge, UK, 1992.

Garratt, J. R.: Review: the atmospheric boundary layer, Earth-Sci. Rev., 37, 89-134, 1994.

Goswami, B. N.: South Asian Monsoon: in Intraseasonal Variability of the Atmosphere- Ocean Climate System, edited by: Lau, W. K. M. and Waliser, D. E., chap. 2, Praxis, Springer Berlin Heidelberg, Germany, 19-61 pp,, 2005.

Guo, J., Miao, Y., Zhang, Y., Liu, H., Li, Z., Zhang, W., He, J., Lou, M., Yan, Y., Bian, L., and Zhai, P.: The climatology of planetary boundary layer height in China derived from radiosonde and reanalysis data, Atmos. Chem. Phys., 16, 13309-13319, https://doi.org/10.5194/acp-16-13309-2016, 2016.

Holt, T. and Raman, S.: A comparison of the significant features of the marine boundary layers over the east central Arabian Sea and the north central Bay of Bengal during MONEX-79, Mausam, 38, 171-176, 1987.

Johnson, R. H., Ciesielski, P. E., and Hart, K. A.: Tropical Inversions near the $0^{\circ} \mathrm{C}$ Level, J. Atmos. Sci., 53, 1838-1855, 1996.

Jordan, N. S., Hoff, R. M., and Bacmeister, J. T.: Validation of Goddard Earth Observing System - version 5 MERRA planetary boundary layer heights using CALIPSO, J. Geophys. Res.Atmos., 115, D24218, https://doi.org/10.1029/2009JD013777, 2010.

Joseph, P. and Sijikumar, S.: Intraseasonal variability of the lowlevel jet stream of the Asian summer monsoon, J. Climate, 17, 1449-1458, 2004.

Kulkarni, J. R., Maheshkumar, R. S., Morwal, S. B., Padma kumari, B., Konwar, M.,Deshpande, C. G., Joshi, R. R., Bhalwankar, R. V., Pandithurai, G., Safai, P. D.,Narkhedkar, S. G., Dani, K. K., Nath, A., Nair, Sathy, Sapre, V. V., Puranik, P. V.,Kandalgaonkar, S. S., Mujumdar, V. R., Khaladkar, R. M., Vijaykumar, R.,Prabha, T. V., and Goswami, B. N.: Cloud Aerosol Interaction and PrecipitationEnhancement Experiment (CAIPEEX): overview and preliminary results, Curr. Sci. India, 102, 413-425, 2012.

Kusuma, G. R., Raman, S., and Prabhu, A.: Boundary-layer heights over the monsoon trough region during active and break phases, Bound.-Lay. Meteorol., 57, 129-138, 1991.

May, P. T., Long, C. N., and Protat, A.: The diurnal cycle of the boundary layer, convection, clouds, and surface radiation in a coastal monsoon environment (Darwin, Australia), J. Climate, 25, 5309-5326, 2012. 
McGrath-Spangler, E. L. and Denning, A. S.: Estimates of North American summertime planetary boundary layer depths derived from space-borne lidar, J. Geophys. Res.-Atmos., 117, D15101, https://doi.org/10.1029/2012JD017615, 2012.

McGrath-Spangler, E. L. and Denning, A. S.: Global seasonal variations of midday planetary boundary layer depth from CALIPSO space-borne LIDAR, J. Geophys. Res.-Atmos., 118, 1226-1233, 2013.

Medeiros, B., Hall, A., and Stevens, B.: What controls the mean depth of the PBL?, J. Climate, 18, 3157-3172, 2005.

Mehta, S. K., Ratnam, M. V., and Krishna Murthy, B.: Multiple tropopauses in the tropics: a cold point approach, J. Geophys. Res.-Atmos., 116, D20105, https://doi.org/10.1029/2011JD016637, 2011.

Mehta, S. K., Ratnam, M. V., Sunilkumar, S. V., Rao, D. N., and Krishna Murthy, B. V.: Diurnal variability of the atmospheric boundary layer height over a tropical station in the Indian monsoon region, Atmos. Chem. Phys., 17, 531-549, https://doi.org/10.5194/acp-17-531-2017, 2017.

Melfi, S., Spinhirne, J., Chou, S., and Palm, S.: Lidar observations of vertically organized convection in the planetary boundary layer over the ocean, J. Clim. Appl. Meteorol., 24, 806-821, 1985.

Miao, Y., Guo, J., Liu, S., Liu, H., Li, Z., Zhang, W., and Zhai, P.: Classification of summertime synoptic patterns in Beijing and their associations with boundary layer structure affecting aerosol pollution, Atmos. Chem. Phys., 17, 3097-3110, https://doi.org/10.5194/acp-17-3097-2017, 2017.

Morwal, S. B., Maheskumar, R. S., Padma Kumari, B., Kulkarni, J. R., and Goswami, B. N.: Cloud microphysical properties over Indianmonsoon regions during CAIPEEX-2009, J. Atmos. Sol.-Terr. Phy., 81, 76-85, 2012.

Muraleedharan, P., Mohankumar, K., and Sivakumar, K.: A study on the characteristics of temperature inversions in active and break phases of Indian summer monsoon, J. Atmos. Sol.-Terr. Phy., 93, 11-20, 2013.

Parasnis, S. and Goyal, S.: Thermodynamic features of the atmospheric boundary layer during the summer monsoon, Atmos. Environ. A Gen., 24, 743-752, 1990.

Prabha, T. V., Karipot, A., Axisa, D., Kumari, B. P., Maheskumar, R. S., Konwar, M., Kulkarni, J. R., and Goswami, B. N.: Scale interactions near the foothills of Himalayas during CAIPEEX, J. Geophys. Res.-Atmos., 117, D10203, https://doi.org/10.1029/2011JD016754, 2012.

Raman, S., Templeman, B., Templeman, S., Holt, T., Murthy, A., Singh, M., Agarwaal, P., Nigam, S., Prabhu, A., and Ameenullah, S.: Structure of the Indian southwesterly pre-monsoon and monsoon boundary layers: observations and numerical simulation, Atmos. Environ. A Gen., 24, 723-734, 1990.

Ramana, M. V., Krishnan, P., Muraleedharan Nair, S., and Kunhikrishnan, P. K.: Thermodynamic structure of the Atmospheric Boundary Layer over the Arabian Sea and the Indian Ocean during pre-INDOEX and INDOEX-FFP campaigns, Ann. Geophys., 22, 2679-2691, https://doi.org/10.5194/angeo-22-26792004, 2004.

Roja Raman, M., Venkat Ratnam, M., Rajeevan, M., Jagannadha Rao, V., and Bhaskara Rao, S. V.: Intriguing aspects of the monsoon low-level jet over peninsular India revealed by high- resolution GPS radiosonde observations, J. Atmos. Sci., 68, 1413-1423, 2011.

Sandeep, A., Rao, T. N., Ramkiran, C., and Rao, S.: Differences in atmospheric boundary-layer characteristics between wet and dry episodes of the Indian summer monsoon, Bound.-Lay. Meteorol., 153, 217-236, 2014.

Sandeep, A., Rao, T. N., and Rao, S. V. B.: A comprehensive investigation on afternoon transition of the atmospheric boundary layer over a tropical rural site, Atmos. Chem. Phys., 15, 76057617, https://doi.org/10.5194/acp-15-7605-2015, 2015.

Satyanarayana Mohan, T. and Narayana Rao, T.: Variability of the thermal structure of the atmosphere during wet and dry spells over southeast India, Q. J. Roy. Meteor. Soc., 138, 1839-1851, 2012.

Schubert, W. H., Ciesielski, P. E., Lu, C., and Johnson, R. H.: Dynamical adjustment of the trade wind inversion layer, J. Atmos. Sci., 52, 2941-2952, 1995.

Seibert, P., Beyrich, F., Gryning, S.-E., Joffre, S., Rasmussen, A., and Tercier, P.: Review and intercomparison of operational methods for the determination of the mixing height, Atmos. Environ., 34, 1001-1027, 2000.

Seidel, D. J., Ao, C. O., and Li, K.: Estimating climatological planetary boundary layer heights from radiosonde observations: comparison of methods and uncertainty analysis, J. Geophys. Res.Atmos., 115, D16113, https://doi.org/10.1029/2009JD013680, 2010.

Sen Gupta, K. and Ramachandran, R.: Tropical atmospheric boundary layer, Proceedings of the Indian National Science Academy, 64, 267-276, 1998.

Stull, R. B.: Introduction to Boundary Layer Meteorology, Kluwer Academic Publishers, Dordrecht, Boston and London, 666 pp., 1988.

Subrahamanyam, D. B. and Ramachandran, R.: Structural characteristics of marine atmospheric boundary layer and its associated dynamics over the Central Arabian Sea during INDOEX, IFP-99 campaign, Curr. Sci. India, 85, 1334-1340, 2003.

Wallace, J. M. and Hobbs, P. V.: Atmospheric Science: an Introductory Survey, Academic press, Elsevier, Burlington, MA 01803, USA, 483 pp., 2006.

Wang, J. and Rossow, W. B.: Determination of cloud vertical structurefrom upper-air observations, J. Appl. Meteorol., 34, 22432258, 1995.

Wang, J., Rossow, W. B., Uttal, T., and Rozendaal, M.: Variability of cloud vertical structure during ASTEX observed from a combination of rawinsonde, radar, ceilometer, and satellite, Mon. Weather Rev., 127, 2484-2502, 1999.

Webster, P. J., Magaña, V. O., Palmer, T. N., Shukla, J., Tomas, R. A., Yanai, M., and Yasunari, T.: Monsoons: Processes, predictability, and the prospects for prediction, J. Geophys. Res., 103, 14451-14510, https://doi.org/10.1029/97JC02719, 1998.

Winker, D. M., Hunt, W. H., and McGill, M. J.: Initial performance assessment of CALIOP, Geophys. Res. Lett., 34, L19803, https://doi.org/10.1029/2007GL030135, 2007.

Winker, D. M., Vaughan, M. A., Omar, A., Hu, Y., Powell, K. A., Liu, Z., Hunt, W. H., and Young, S. A.: Overview of the CALIPSO mission and CALIOP data processing algorithms, J. Atmos. Ocean. Tech., 26, 2310-2323, 2009.

Zhang, Q., Zhang, J., Qiao, J., and Wang, S.: Relationship of atmospheric boundary layer depth with thermodynamic processes at 
the land surface in arid regions of China, Sci. China Earth Sci., 54, 1586, https://doi.org/10.1007/s11430-011-4207-0, 2011.

Zhang, W., Guo, J., Miao, Y., Liu, H., Zhang, Y., Li, Z., and Zhai, P.: Planetary boundary layer height from CALIOP compared to radiosonde over China, Atmos. Chem. Phys., 16, 9951-9963, https://doi.org/10.5194/acp-16-9951-2016, 2016.
Zhou, X. and Geerts, B.: The influence of soil moisture on the planetary boundary layer and on cumulus convection over an isolated mountain, Part I: Observations, Mon. Weather Rev., 141, 10611078, 2013. 